\title{
Smelling the Dark Proteome: Functional Characterization of PITH Domain-Containing Protein 1 (C1orf128) in Olfactory Metabolism
}

Mercedes Lachén-Montes, Naroa Mendizuri, Karina Ausín, Alberto Pérez-Mediavilla, Mikel Azkargorta, Ibon Iloro, Felix Elortza, Hiroyuki Kondo, Izumi Ohigashi, Isidre Ferrer, Rafael de la Torre, Patricia Robledo, Joaquín Fernández-Irigoyen, ${ }^{\dagger}$ and Enrique Santamaría* ${ }^{\dagger}$

Cite This: J. Proteome Res. 2020, 19, 4826-4843

Read Online

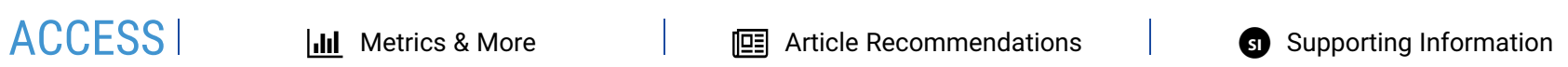

ABSTRACT: The Human Proteome Project (HPP) consortium aims to functionally characterize the dark proteome. On the basis of the relevance of olfaction in early neurodegeneration, we have analyzed the dark proteome using data mining in public resources and omics data sets derived from the human olfactory system. Multiple dark proteins localize at synaptic terminals and may be involved in amyloidopathies such as Alzheimer's disease $(\mathrm{AD})$. We have characterized the dark PITH domain-containing protein 1 (PITHD1) in olfactory metabolism using bioinformatics, proteomics, in vitro and in vivo studies, and neuropathology. PITHD1 $1^{-9}$ mice exhibit olfactory bulb (OB) proteome changes related to synaptic transmission, cognition, and memory. OB PITHD1 expression increases with age in wild-type (WT) mice and decreases in $\operatorname{Tg} 2576 \mathrm{AD}$ mice at late stages. The analysis across 6 neurological disorders reveals that olfactory tract (OT) PITHD1 is specifically upregulated in human AD. Stimulation of olfactory neuroepithelial (ON) cells with PITHD1 alters the ON phosphoproteome, modifies the proliferation rate, and induces a pro-inflammatory phenotype.

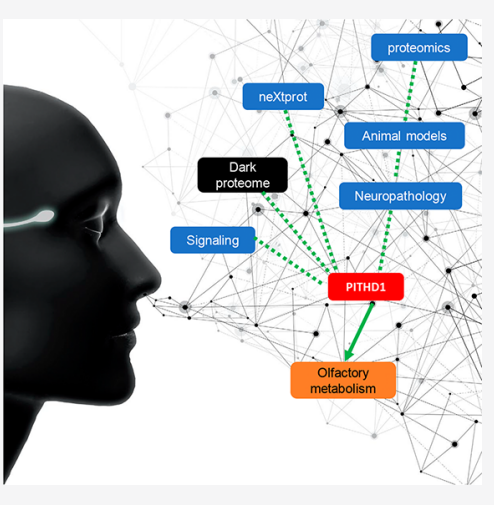
This workflow applied by the Spanish C-HPP and Human Brain Proteome Project (HBPP) teams across the ON-OB-OT axis can be adapted as a guidance to decipher functional features of dark proteins. Data are available via ProteomeXchange with identifiers PXD018784 and PXD021634.

KEYWORDS: Human Proteome Project, olfaction, neurodegeneration, uPE1, dark proteome, PITHD1

\section{INTRODUCTION}

The Human Proteome Project (HPP) is an initiative of the Human Proteome Organization (HUPO) aiming to characterize the human proteome and make this knowledge available to the broad scientific community. ${ }^{1}$ During the past years, the efforts of the international Chromosome-Centric HPP (CHPP) consortium have improved the mapping and annotation of protein components of each human chromosome. ${ }^{2,3}$ In parallel, the international Biology and Disease-driven HPP (B/ D-HPP) initiatives have organized the human proteome across human cell-tissue-organ axis, establishing functional modules through the integration of technology and biological knowledge to study human diseases. ${ }^{4}$ Although the annotation of the human proteome has made significant progress, caveats exist regarding the availability of information related to protein function. ${ }^{5}$ NeXtProt, the essential reference knowledgebase for the HPP, ${ }^{6}$ contains 1813 dark proteins (release 2020-01-17) corresponding to 559 missing proteins and 1254 proteins with high confidence at the protein level (PE1) but considered as functionally uncharacterized (uPE1)., This "dark proteome" has not revealed any function by database searching, domain analysis, intrinsic feature analysis, similarity analysis, and metabolic pathway involvement between others. ${ }^{8}$ As a new avenue toward the completion and annotation of the human proteome, the C-HPP consortium has recently launched the neXt-CP50 Pilot Project ${ }^{5}$ for functional characterization of identified proteins with insufficiently known function. An experimental workflow based on multiomics analyses, bioinformatics, immunological detections, and in vitro and in vivo studies has been recently proposed, ${ }^{5}$ in order to collaborate with $\mathrm{B} / \mathrm{D}$ teams to enhance the annotation of UPE1 proteins in specific biological scenarios.

In the context of the $\mathrm{B} / \mathrm{D}$ oriented branch of the Human Brain Proteome Project (HBPP), ${ }^{9}$ the work presented in this paper originates from members of the Spanish C-HPP initiative and aims to characterize the dark proteome in human olfactory system. Taking into account the relevance of the smell sense in the early diagnosis of neurodegenerative diseases, ${ }^{10}$ we have analyzed the expression profile of the dark proteome (neXtProt release 2020-01-17; query: NXQ 00022) across public

Special Issue: Human Proteome Project 2020

Received: June 22, 2020

Published: November 13, 2020

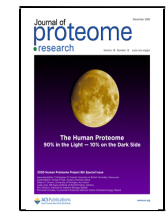


proteomic and transcriptomic data derived from primary olfactory areas such as olfactory bulb (OB) and cleft mucus as well as from specific brain/OB cell lineages. Specifically, we have focused our attention on the uPE1 PITH (C-terminal proteasome-interacting domain of thioredoxin-like) domaincontaining protein 1 (PITHD1; C1orf128), previously considered as a component of the human central proteome. ${ }^{11}$ Although it has been related to megakaryopoiesis, ovarian carcinoma, and male fertilization, ${ }^{12-14}$ functional features associated with PITHD1 gene are insufficiently known.

Previous reports pointed out that PITHD1 expression is altered in Alzheimer's disease ( $\mathrm{AD}$ ) and Parkinson's disease (PD) at the level of the OB. ${ }^{15,16}$ In this study, we have used an experimental workflow combining neuropathological diagnosis, coregulation maps, physical and functional interaction data, transgenic models, intracellular and extracellular proteomics and immunohistochemical and biochemical approaches to partially decipher the PITHD1 function in olfactory metabolism. Together with a cross-disease study to monitor olfactory PITHD1 expression across multiple neurological phenotypes with different sensitivity to olfactory dysfunction as well as in a mouse $\mathrm{AD}$ model, in vitro experiments have allowed us to demonstrate that PITHD1 interferes with the differentiation state of the human olfactory neuroepithelial (ON) cells, inducing a pro-inflammatory phenotype in parallel with protein expression changes associated with the establishment of the endothelial barrier, neural precursor cell proliferation, JAKSTAT pathway, and respiratory electron transport.

\section{MATERIALS AND METHODS}

\section{Materials}

The following reagents and materials were used. Anti-PITHD1 (HPA016936), antipolyhistidine-peroxidase (A7058-1VL) and anti-c-Myc (M4439) antibodies were purchased from Sigma. Human rPITHD1 was purchased from MyBiosource (MBS1307571). The protein was expressed in E. coli and Nterminal His-tagged and C-terminal His-tagged in aseptic processing and endotoxin removal conditions. Cytokine antibody arrays were obtained from Abcam (ab133998) and human phosphokinase antibody arrays from R\&D systems (ARY003B). Electrophoresis reagents were purchased from Biorad and trypsin from Promega. TMT kit was purchased from Thermo (90064).

\section{Human Samples}

According to the Spanish Law 14/2007 of Biomedical Research, informed written consent forms of the Neurological Tissue Bank of IDIBAPS-Hospital Clinic (Barcelona, Spain) were obtained for research purposes from relatives of patients included in this study. The study was conducted in accordance with the Declaration of Helsinki and all assessments, post-mortem evaluations, and procedures were previously approved by the Clinical Ethics Committee of Navarra Health Service (no. 2016/ 36). In all cases (Supplementary Table S1) neuropathological assessments were performed according to standardized neuropathological scoring/grading systems. ${ }^{17-25}$

\section{Murine Models}

Transgenic mice ( $\operatorname{Tg} 2576)$ overexpressing human amyloid precursor protein (hAPP), carrying the Swedish (K670N/ M671L) familial $\mathrm{AD}$ mutation and under control of the prion promoter, ${ }^{26}$ were used. Mice were on an inbred C57BL/6/SJL genetic background. The animals were maintained in positive pressure-ventilated racks at $25 \pm 10 \mathrm{C}$ with a $12 \mathrm{~h}$ light/dark cycle, fed ad libitum with a standard rodent pellet diet (Global Diet 2014; Harlan Laboratories, Indianapolis, IN, USA) and had free access to filtered and UV-irradiated water. All animal care and experimental procedures were in accordance with European and Spanish regulations (86/609/CEE; RD1201/2005) and were approved by the Ethical Committee of the University of Navarra (no. 018/05). At least three WT and three Tg2576 transgenic mice per stage (2-, 6-, and 18-month-old) were used. The progressive development of $\mathrm{AD}$ signs in our colony has been previously described. ${ }^{27}$ PITHD1-deficient (PITHD $1^{-/-}$) mice (accession no. CDB1274K) were generated as previously described. ${ }^{14}$ All mouse experiments were performed with consent from the Animal Experimentation Committee of Tokushima University (T28-58).

Immunohistochemistry

Under xylazine/ketamine anesthesia, animals were perfused transcardially with saline for $3 \mathrm{~min}$ at a $11 \mathrm{~mL} / \mathrm{min}$ flow, and $4 \%$ paraformaldehyde in phosphate buffered saline (PBS) for $2 \mathrm{~min}$ at a $9 \mathrm{~mL} / \mathrm{min}$ flow. After perfusion, brains were removed, postfixed in $4 \%$ paraformaldehyde for $1 \mathrm{~h}$ at room temperature and cryoprotected in 30\% sucrose solution in PBS overnight at $4 \circ \mathrm{C}$. Immunohistochemistry analysis were performed as previously described. ${ }^{28} \mathrm{OB}$ and hippocampal sections were incubated overnight with the anti-PITHD 1 antibody (HPA016936) diluted 1:350 in PBS $0.125 \mathrm{M}$ ( $\mathrm{pH} 7.4$ ), 0.5\% Triton X-100, 0.1\% BSA and 5\% normal goat sera. After washing $(3 \times 5 \mathrm{~min})$ in PBS, sections were incubated for $30 \mathrm{~min}$ with biotinylated goat antimouse secondary antibody (DakoCytomation, Glostrup, Denmark) diluted 1:500 in PBS. The sections were then processed using the avidin-biotin-peroxidase complex (Vectastain kit, Vector Laboratories, Burlingame, CA, USA) and reacted with $0.05 \%$ 3,3'-diaminobenzidine tetrahydrochloride $(\mathrm{DAB})$ and $0.015 \% \mathrm{H}_{2} \mathrm{O}_{2}$ in $50 \mathrm{mM}$ Tris $\mathrm{HCl}$, $\mathrm{pH}$ 7.2. After washing in deionized water, sections were mounted on gelatinized slides, counterstained with Thionine at $60{ }^{\circ} \mathrm{C}$ (Panreac Quimica, Barcelona, Spain) and coverslipped with DPX (VWR, Dublin, Ireland).

\section{Cell Culture}

ON samples were obtained from control subjects as previously described. ${ }^{29}$ The study was reviewed and approved by the local institutional ethics committee (no. PI_2019/108). After humidification of the nasal cavity, two separate sterile interdental brushes were used to obtain samples from the lower and middle turbinate, and were placed inside Eppendorf tubes with $250 \mu \mathrm{L}$ of cold Dulbecco's Modified Eagle Medium/ Ham F-12 (DMEM/F12) containing 10\% FBS, 2\% glutamine and $1 \%$ streptomycin-penicillin (supplemented medium) (GibcoBRL). This procedure was performed separately for both nostrils. The nasal exfoliates were initially placed in cold Dulbecco's Modified Eagle Medium/Ham F-12 (DMEM/F12) containing $10 \%$ FBS, $2 \%$ glutamine and $1 \%$ streptomycinpenicillin (GibcoBRL). ON cells suspensions were disaggregated mechanically, and primary cultures were established as previously described. ${ }^{30}$ Cells were grown for 3 weeks in supplemented medium at $37{ }^{\circ} \mathrm{C}$ and $5 \% \mathrm{CO}_{2}$ before passaging into flasks (Thermo Scientific, Madrid, Spain). Cells were dissociated with $0.25 \%$ trypsin (GibcoBRL) replated at 4000 cells $/ \mathrm{cm}^{2}$ into $75 \mathrm{~cm}^{2}$ flasks and cultured in supplemented medium. Then, cells were expanded by passage and banked down in aliquots after harvest, followed by storage in liquid nitrogen with DMEM/F12, 2\% glutamine, 1\% streptomycin- 
penicillin, 20\% FBS and 10\% dimethyl sulfoxide (Sigma-Aldrich, Madrid, Spain). Frozen aliquots of ON cells at passage 4 were used. $1 \times 10^{6}$ and $1 \times 10^{6} \mathrm{ON}$ cells in triplicates were used for protein arrays and proteomic analysis, respectively. In all cases, $40 \mathrm{uM}$ of human rPITHD1 was directly added to the cell media during the indicated periods of time. Cell media was collected, and cells were washed 3 times with $1 \times$ cold PBS, harvested and immediately frozen in liquid nitrogen. Additionally, cell viability was determined by crystal violet assay.

\section{Sample Preparation for ON Proteomic Analysis}

ON cells and PITHD1-treated ON cells were harvested after 24 h (triplicates). After centrifugation ( $5 \mathrm{~min}, 300 \mathrm{~g}$ ), supernatants were discarded, and pellets were washed with PBS three times to remove remaining media. Cellular pellets were resuspended in lysis buffer containing $7 \mathrm{M}$ urea, $2 \mathrm{M}$ thiourea, $50 \mathrm{mM}$ DTT and incubated on ice for $30 \mathrm{~min}$, spinning and vortexing each $10 \mathrm{~min}$. After sonication, homogenates were spun down at $20000 \mathrm{~g}$ for 1 h. Protein concentration was measured in the supernatants with the Bradford assay kit (Biorad).

Tandem Mass Tag (TMT)-Based Quantitative Proteomics Using Trapped Ion Mobility Spectrometry (TIMS-TOF)

A shotgun comparative proteomic analysis of ON cells was performed combining TMT labeling and TIMS-TOF mass spectrometry. Briefly, after a precipitation step using the Cleanup kit (Biorad ref. 1632130), samples were resuspended in $6 \mathrm{M}$ urea and $100 \mathrm{mM}$ TEAB. Then, equal amounts of $\mathrm{ON}$ protein extract $(50 \mu \mathrm{g})$ were reduced with $200 \mathrm{mM} \mathrm{TCEP}$ during $1 \mathrm{~h}$ at $55{ }^{\circ} \mathrm{C}$. Cysteine residues were alkylated with $375 \mathrm{mM}$ IAA at room temperature for $30 \mathrm{~min}$ in darkness. Protein enzymatic cleavage was carried out with trypsin (Promega; 1:40, w/w) at $37^{\circ} \mathrm{C}$ for $16 \mathrm{~h}$. Then, after performing a peptide desalting step (Thermo Scientific, ref 89852), each tryptic digest was labeled according to the manufacturer's instructions with one isobaric tag: Tag 126, control 1; tag 127, control 2; tag 128, control 3; tag 129 treated 1 ; tag 130, treated 2; and tag 131, treated 3. After $1 \mathrm{~h}$ of incubation, each set of labeled samples was independently pooled and evaporated in a vacuum centrifuge.

\section{MS Acquisition and Data Processing}

Pooled samples were separated in a HPLC by High $\mathrm{pH}$ reverse phase chromatography using an Agilent Technologies 1200 series, equipped with a Phenomenex Gemini C18 column (150 $\mathrm{mm} \times 2 \mathrm{~mm}$ ID, 5um). A chromatographic linear ramp of 30 $\min (5$ to $60 \% \mathrm{ACN})$ was used with a flow rate of $500 \mu \mathrm{L} / \mathrm{min}$, followed by a washing step of $15 \mathrm{~min}$ at $86 \% \mathrm{ACN}$. Mobile phase A was composed by water containing $10 \mathrm{mM}$ Ammonium formate, $\mathrm{pH} 10$ and mobile phase $\mathrm{B}$ was composed by $90 \% \mathrm{ACN}$ containing $10 \mathrm{mM}$ Ammonium formate, $\mathrm{pH}$ 10. Automatic sampling collection was performed each minute during ramp and washing steps. Up to 36 fractions were finally collected (500 $\mu \mathrm{L}$ each). Low-complexity fractions were pooled, whereas highcomplexity samples (based on the UV signal) were analyzed on their own. A total of 25 different fractions were evaporated using SpeedVac (Christ corp.), resuspended (in 0.1\% FA) and loaded onto a novel hybrid trapped ion mobility spectrometryquadrupole time-of-flight mass spectrometer (TIMS-TOF Pro with PASEF, Bruker Daltonics) coupled online to a nanoElute liquid chromatograph (Bruker Daltonics). Samples (approximately $200 \mathrm{ng}$ ) were loaded in a nanoEASY trap (Waters) and then resolved in a $15 \mathrm{~cm}$ nanoelute FIFTEEN C18 analytical column (Bruker Daltonics) at $300 \mathrm{~nL} / \mathrm{min}$ with a $15 \mathrm{~min}$ gradient $(2-35 \% \mathrm{ACN})$. Column was heated to $40{ }^{\circ} \mathrm{C}$ using an oven. Mass spectrometer resolution was 50000 at $\mathrm{m} / z=1222$, and ions between 100 and $1700 \mathrm{~m} / z$ and charge state $2 / 3$ (selected with the polygon) with an intensity higher than 2500 were specifically selected for fragmentation. Masses below 700 $\mathrm{m} / z$ were isolated with a window of $2 \mathrm{Th}$, and those above 800 $\mathrm{m} / z$ with a window of $3 \mathrm{Th}$, whereas the isolation widths for masses between 700 and $800 \mathrm{~m} / z$ were extrapolated from values between those 2-3 Th. Mass spectrometer operated in PASEF mode, performing $10 \mathrm{PASEF}$ MS/MS scans for each survey scan. CID was used for the fragmentation of peptides with a target precursor intensity set at 2500. Collision energy (CE) for peptides with mobility below $0.8 \mathrm{~V} \cdot \mathrm{s} / \mathrm{cm}^{2}$ was $31.92 \mathrm{eV}$, whereas for those with mobility above $1.56 \mathrm{~V} \cdot \mathrm{s} / \mathrm{cm}^{2}$ the $\mathrm{CE}$ was $51.24 \mathrm{eV}$. $\mathrm{CE}$ for peptides with mobility in between those values is extrapolated. However, TIMS stepping was used to analyze the TMT-labeled peptides, meaning that each precursor was fragmented twice with specific parameters: once for reporter ion analysis (Collision Rf $700 \mathrm{Vpp}$, collision energy 140\%, transfer time $40 \mu \mathrm{s}$, prepulse storage time $8 \mu \mathrm{s}$ ) and once for peptide backbone analysis (Collision Rf $1500 \mathrm{Vpp}$, collision energy $100 \%$, transfer time $60 \mu \mathrm{s}$, prepulse storage time $12 \mu \mathrm{s}$ ). Dynamic exclusion was applied for $0.4 \mathrm{~min}$ with a mass width of $0.015 \mathrm{~m} / z$ and a mobility window of $0.015 \mathrm{~V} \cdot \mathrm{s} / \mathrm{cm}^{2}$, although it was reconsidered when current intensity/previous intensity is greater than 4. Protein identification and quantification was carried out using PEAKS software v.10.5 (Bioinformatics solutions). Searches were carried out against Human Uniprot database (version 2020-02-22 April 2020; 20366 entries) with precursor and fragment tolerances of $20 \mathrm{ppm}$ and $0.05 \mathrm{Da}$. Purity correction was performed following the instructions of the manufacturer. Peptide-spectra matches were filtered at FDR $<1 \%$, leading to a $2 \%$ FDR at peptide level, using a decoy-fusion approach. In this approach target and decoy entries of the same protein are concatenated and further separated after the search by checking whether they come from the first or the second half of each concatenated sequence. Thus, the FDR is calculated as the ratio between the number of decoy hits and the number of target hits above a given score threshold, where decoy hits are only kept if they only match decoy protein groups or the decoy protein score is higher than that of its counterpart target protein. ${ }^{31}$ Target proteins were cut off using a $-10 \log (p)$ threshold of 27.5 in order to keep protein-level FDR at $1 \%$. The Perseus software (1.6.10.50) was used for statistical analysis and data visualization. Protein quantification was considered valid with at least two unique peptides for each protein and statistical significance was calculated by a two-way Student $t$ test $(p<$ 0.05 ). A fold-change (FC) of $20 \%$ was considered to select differential expressed proteins.

\section{SWATH-MS Proteomics Applied to OB Derived from PITHD1 ${ }^{-/-}$Mice: MS/MS Library Generation}

Wild-type and PITHD1 ${ }^{-/-}$OB specimens were homogenized in lysis buffer containing $7 \mathrm{M}$ urea, $2 \mathrm{M}$ thiourea, and $50 \mathrm{mM}$ DTT (6-weeks and 12-weeks-old, $n=3$ per group). The homogenates were spun down at $100000 \mathrm{~g}$ for $1 \mathrm{~h}$ at $15{ }^{\circ} \mathrm{C}$. Protein concentration was measured using Bradford assay kit (Biorad). As an input for generating the SWATH-MS assay library, a pool of 12 samples $(2.5 \mu \mathrm{g} /$ sample $)$ derived from 6-weeks-old mice ( $n=3$ /group) and 12-weeks-old mice ( $n=3$ /group) was used. Protein extracts $(30 \mu \mathrm{g})$ were diluted in Laemmli sample buffer and loaded into a $0.75 \mathrm{~mm}$ thick polyacrylamide gel with a $4 \%$ stacking gel casted over a $12.5 \%$ resolving gel. Total gel was stained with Coomassie Brilliant Blue and 12 equals slides from 
the pooled sample were excised from the gel and transferred into $1.5 \mathrm{~mL}$ Eppendorf tubes. Protein enzymatic cleavage was carried out with trypsin (Promega; $1: 20, \mathrm{w} / \mathrm{w}$ ) at $37{ }^{\circ} \mathrm{C}$ for $16 \mathrm{~h}$ as previously described. ${ }^{32}$ Peptide mixture was dried in a speed vacuum for $20 \mathrm{~min}$. Purification and concentration of peptides were performed using C18 Zip Tip Solid Phase Extraction (Millipore). Peptides recovered from in-gel digestion processing were reconstituted into a final concentration of $0.5 \mu \mathrm{g} / \mu \mathrm{L}$ of $2 \%$ ACN, 0.5\% FA, 97.5\% Milli-Q-water prior to mass spectrometric analysis. MS/MS data sets for spectral library generation were acquired on a Triple TOF 5600+ mass spectrometer (Sciex, Canada) interfaced to an Eksigent nanoLC ultra 2D pump system (SCIEX, Canada) fitted with a $75 \mu \mathrm{m}$ ID column (Thermo Scientific $0.075 \times 250 \mathrm{~mm}$, particle size $3 \mu \mathrm{m}$ and pore size $100 \AA$ ). Prior to separation, the peptides were concentrated on a C18 precolumn (Thermo Scientific $0.1 \times 50 \mathrm{~mm}$, particle size $5 \mu \mathrm{m}$ and pore size $100 \AA$ ). Mobile phases were $100 \%$ water $0.1 \%$ formic acid (FA) (buffer A) and 100\% Acetonitrile 0.1\% FA (buffer B). Column gradient was developed in a gradient from $2 \% \mathrm{~B}$ to $40 \% \mathrm{~B}$ in $120 \mathrm{~min}$. Column was equilibrated in 95\% B for $10 \mathrm{~min}$ and $2 \% \mathrm{~B}$ for $10 \mathrm{~min}$. During all processes, the precolumn was in line with column and flow was maintained all along the gradient at $300 \mathrm{~nL} / \mathrm{min}$. Output of the separation column was directly coupled to nanoelectrospray source. MS1 spectra was collected in the range of $350-1250 \mathrm{~m} / z$ for $250 \mathrm{~ms}$. The 35 most intense precursors with charge states of 2 to 5 that exceeded 150 counts per second were selected for fragmentation, rolling collision energy was used for fragmentation, and MS2 spectra were collected in the range of $230-1500 \mathrm{~m} / z$ for $100 \mathrm{~ms}$. The precursor ions were dynamically excluded from reselection for $15 \mathrm{~s}$. MS/MS data acquisition was performed using AnalystTF 1.7 (Sciex) and spectra files were processed through ProteinPilot v5.0 search engine (Sciex) using Paragon Algorithm (v.4.0.0.0) $)^{33}$ for database search. To avoid using the same spectral evidence in more than one protein, the identified proteins were grouped based on MS/MS spectra by the Progroup algorithm, regardless of the peptide sequence assigned. The protein within each group that could explain more spectral data with confidence was depicted as the primary protein of the group. False discovery rate was performed using a nonlinear fitting method ${ }^{34}$ and displayed results were those reporting a $1 \%$ Global false discovery rate or better.

SWATH-MS Proteomics of OB Derived from PITHD $1^{-/-}$Mice: Quantitative Analysis

Protein extracts $(20 \mu \mathrm{g})$ from each sample were reduced by addition of DTT to a final concentration of $10 \mathrm{mM}$ and incubation at $25^{\circ} \mathrm{C}$ for $1 \mathrm{~h}$. Subsequent alkylation by $30 \mathrm{mM}$ iodoacetamide was performed for $1 \mathrm{~h}$ in the dark. An additional reduction step was performed by $30 \mathrm{mM}$ DTT, allowing the reaction to stand at $25^{\circ} \mathrm{C}$ for $1 \mathrm{~h}$. The mixture was diluted to 0.6 $\mathrm{M}$ urea using Milli-Q-water, and after trypsin addition (Promega) (enzyme:protein, 1:50 w/w), the sample was incubated at $37{ }^{\circ} \mathrm{C}$ for $16 \mathrm{~h}$. Digestion was quenched by acidification with acetic acid. The digestion mixture was dried in a SpeedVac. Purification and concentration of peptides was performed using C18 Zip Tip Solid Phase Extraction (Millipore). The peptides recovered were reconstituted into a final concentration of $0.5 \mu \mathrm{g} / \mu \mathrm{L}$ of $2 \% \mathrm{ACN}, 0.5 \% \mathrm{FA}, 97.5 \%$ Milli-Q-water prior to mass spectrometric analysis. For SWATH-MS-based experiments, the instrument (Sciex TripleTOF 5600+) was configured as described by Gillet et al. ${ }^{35}$ Briefly, the mass spectrometer was operated in a looped product ion mode. In this mode, the instrument was specifically tuned to allow a quadrupole resolution of $\mathrm{Da} /$ mass selection. The stability of the mass selection was maintained by the operation of the Radio Frequency (RF) and Direct Current (DC) voltages on the isolation quadrupole in an independent manner. Using an isolation width of $16 \mathrm{Da}$ (15 Da of optimal ion transmission efficiency and $1 \mathrm{Da}$ for the window overlap), a set of 37 overlapping windows were constructed covering the mass range 450-1000 Da. In this way, $1 \mu \mathrm{L}$ of each sample was loaded onto a trap column (Thermo Scientific $0.1 \times 50 \mathrm{~mm}$, particle size 5 $\mu \mathrm{m}$ and pore size $100 \AA$ ) and desalted with $0.1 \%$ TFA at $3 \mu \mathrm{L} /$ min during $10 \mathrm{~min}$. The peptides were loaded onto an analytical column (Thermo Scientific $0.075 \times 250 \mathrm{~mm}$, particle size $3 \mu \mathrm{m}$ and pore size $100 \AA$ ) equilibrated in $2 \%$ acetonitrile $0.1 \%$ FA. Peptide elution was carried out with a linear gradient of 2 to $40 \%$ $\mathrm{B}$ in $120 \mathrm{~min}$ (mobile phases A: $100 \%$ water $0.1 \%$ formic acid (FA) and B: $100 \%$ Acetonitrile $0.1 \%$ FA) at a flow rate of 300 $\mathrm{nL} / \mathrm{min}$. Eluted peptides were infused in the mass spectrometer. The Triple-TOF was operated in swath mode, in which a $0.050 \mathrm{~s}$ TOF MS scan from 350 to $1250 \mathrm{~m} / z$ was performed, followed by $0.080 \mathrm{~s}$ product ion scans from 230 to $1800 \mathrm{~m} / z$ on the 37 defined windows $(3.05 \mathrm{~s} /$ cycle). Collision energy was set to optimum energy for a $2+$ ion at the center of each SWATH block with a $15 \mathrm{eV}$ collision energy spread. The mass spectrometer was always operated in high sensitivity mode. The resulting ProteinPilot group file from library generation was loaded into PeakView (v2.1, Sciex) and peaks from SWATH runs were extracted with a peptide confidence threshold of $99 \%$ confidence (Unused Score $\geq 1.3$ ) and a false discovery rate (FDR) lower than 1\%. For this, the MS/MS spectra of the assigned peptides was extracted by ProteinPilot, and only the proteins that fulfilled the following criteria were validated: (1) peptide mass tolerance lower than $10 \mathrm{ppm}$, (2) 99\% of confidence level in peptide identification, and (3) complete b/ $y$ ions series found in the MS/MS spectrum. Only proteins quantified with at least two unique peptides were considered. The quantitative data obtained by PeakView were analyzed using Perseus software ${ }^{36}$ for statistical analysis and data visualization.

\section{Bioinformatics}

To obtain in silico biological features of PITHD1, multiple bioinformatic resources were used: (i) GOA Database for Gene Ontology annotation, ${ }^{37}$ (ii) PhosphoSitePlus for PTM profiling, $^{38}$ (iii) BioGRID database for protein interactions, ${ }^{39}$ (iv) ExoCarta/Vesiclepedia for exosomal/vesicle cargo annotation, ${ }^{40,41}$ and (v) Proteomics DB, PeptideAtlas and Human Protein Atlas (HPA) for expression/detection analysis in human fluids, cell lines and tissues. ${ }^{42-44}$ The PITHD1 coregulated proteome map and its functionality was generated using ProteomeHD, STRING and Metascape tools. ${ }^{4-47}$

\section{Protein Arrays}

For the secretome analysis, a dot-blot protein array was used for cytokine profiling (Abcam). Briefly, membranes with 80 cytokine antibodies were blocked with the manufacturer's blocking buffer at room temperature (RT) for $30 \mathrm{~min}$, and incubated overnight with $1 \mathrm{~mL}$ of undiluted cell-cultured media from control and PITHD1-treated ON cells during $24 \mathrm{~h}(n=3$ / condition). After washing, a biotinylated anticytokine antibody mixture was added to the membranes followed by incubation with HRP-conjugated streptavidin and then exposed to the manufacturer's peroxidase substrate. For phosphokinome analysis, the Proteome Profiler Array (R \&D Systems) was 
A

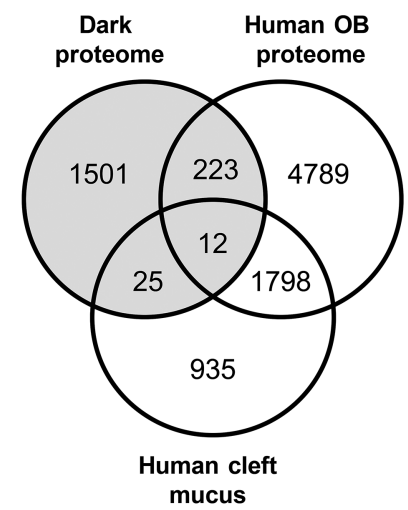

C

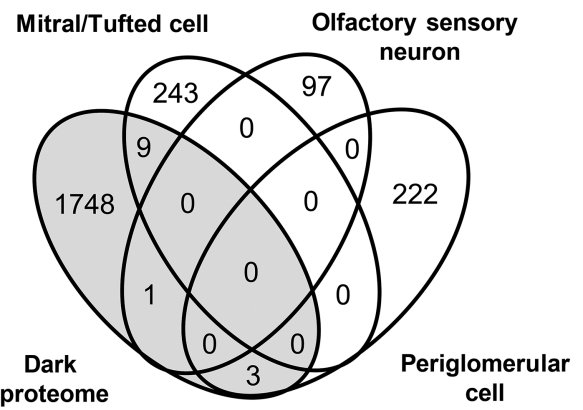

D

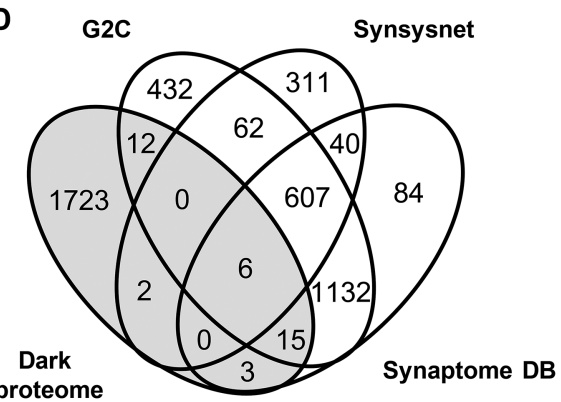

B
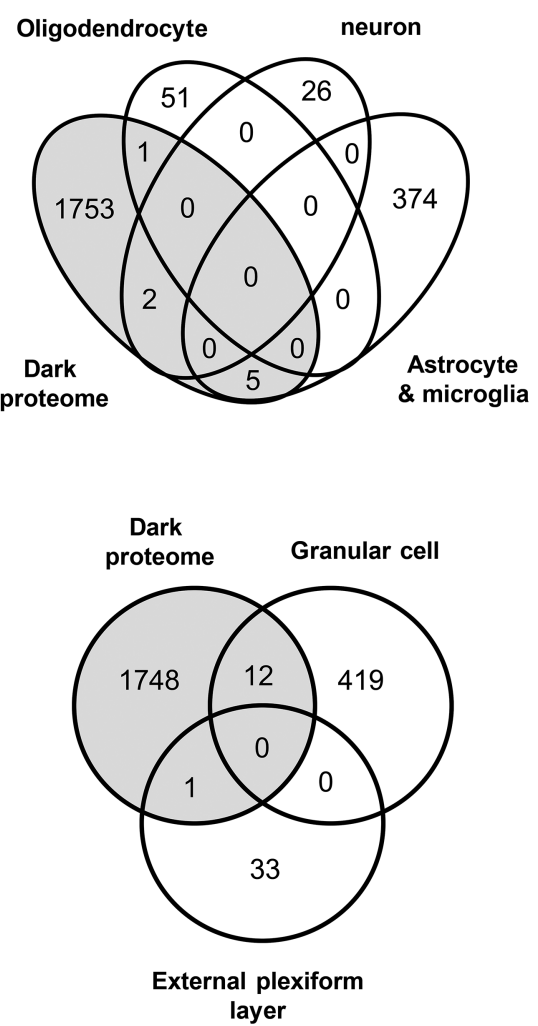

E

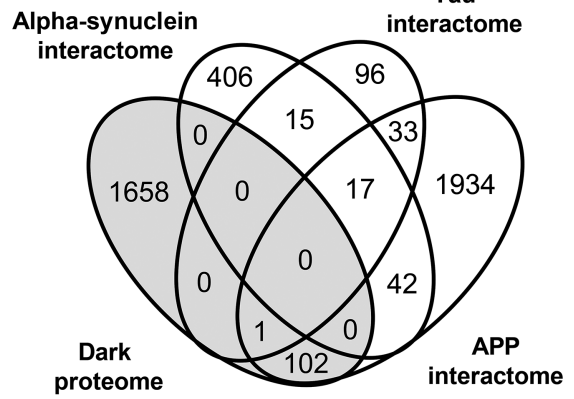

Figure 1. Representation of the dark proteome across olfactory structures, cell types and interactomes for neuropathological substrates. (A) Intersection of proteins derived from proteomic expression profiling of human $\mathrm{OB}$ and cleft mucus respect to the dark proteome considered by NeXtProt (2020-17-01 release). (B) Comparison of the actual dark proteome with murine cell type-enriched markers for four cell types derived from mouse (neurons, oligodendrocytes, astrocytes, and microglia) previously obtained by proteomics. ${ }^{50}(\mathrm{C})$ Cluster-enriched genes in specific murine mouse OB cell layers (mitral/tufted layer, olfactory sensory neurons, periglomerular layer, granular layer and external plexiform layer ${ }^{51}$ that correspond to components of the dark proteome. (D) Venn diagram representing the overlap between the "synaptic proteome" composed by the three major databases on synaptic proteins (C2G, SynsysNet, and Synaptome DB) and the dark proteome. (E) Interlocking of dark proteome with the experimentally validated interactors for neuropathological substrates like APP, MAPT, and SNCA. In all cases, numbers represent the number of shared proteins in the respective overlapping areas.

used according to the manufacturer instructions. Cell lysates derived from control and PITHD1-treated ON cells during $1 \mathrm{~h}$. $(n=3)$ were diluted and incubated overnight with the Human Phospho-Kinase Array, that contains 43 different capture antibodies printed in duplicate. The arrays were washed to remove unbound proteins followed by incubation with a cocktail of biotinylated detection antibodies. Streptavidin-HRP and chemiluminescent detection reagents were applied, and a signal was produced at each capture spot corresponding to the amount of phosphorylated protein bound. For both protein array platforms, chemiluminescence signals were quantified with the ImageQuant ECL system (BioRad) and normalized to the positive control signals. The Perseus software (version 1.5.6.0) was used for statistical analysis. ${ }^{36}$

\section{Western Blotting}

Equal amounts of protein $(10 \mu \mathrm{g})$ were resolved in $4-15 \%$ stain free SDS-PAGE gels (Biorad). Protein extracts derived from ON cells and $\mathrm{OB}$ specimens were electrophoretically transferred onto nitrocellulose membranes using a Trans-blot Turbo transfer system (up to $25 \mathrm{~V}, 7 \mathrm{~min}$ ) (BioRad). Membranes were probed with primary antibodies at 1:1000 dilution in 5\% nonfat milk or BSA according to manufacturer instructions. After incubation with the appropriate horseradish peroxidaseconjugated secondary antibody (1:5000), the immunoreactivity was visualized by enhanced chemiluminescence (PerkinElmer) 


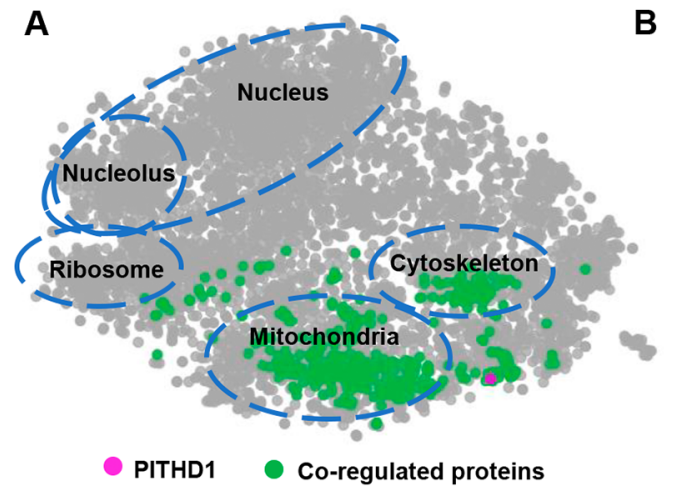

PITHD1 Co-regulated proteins

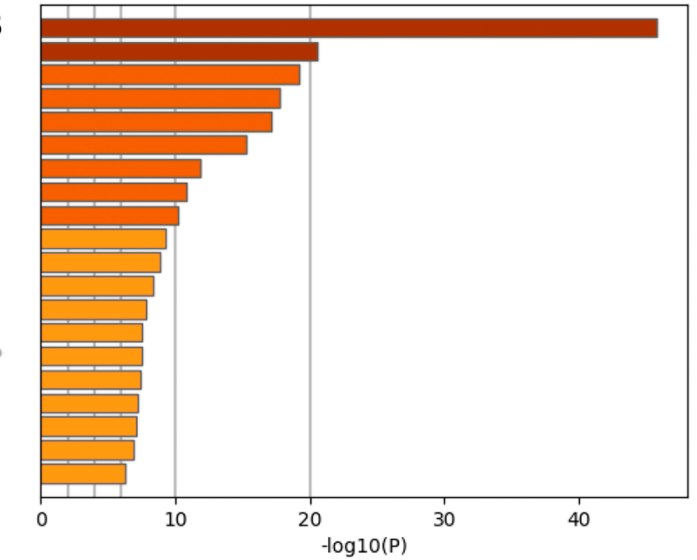

Nucleotide metabolism Mitochondrial transport Macroautophagy

ER to Golgi vesicle-mediated transport Cofactor metabolism Aerobic respiration

Respiratory chain complexI (lambda)

Organelle localization

Protein localization

Endosomal transport

Small molecule catabolism

Respiratory chain complex I (beta)

Intracellular $\mathrm{pH}$ reduction

TP53 regulates metabolic genes

Multivesicular body assembly

Heme metabolism

AXIN/LKB1-AMPK complex

Ribosome disassembly

Protein localization to mitocondria

Cellular aldehyde metabolism

C

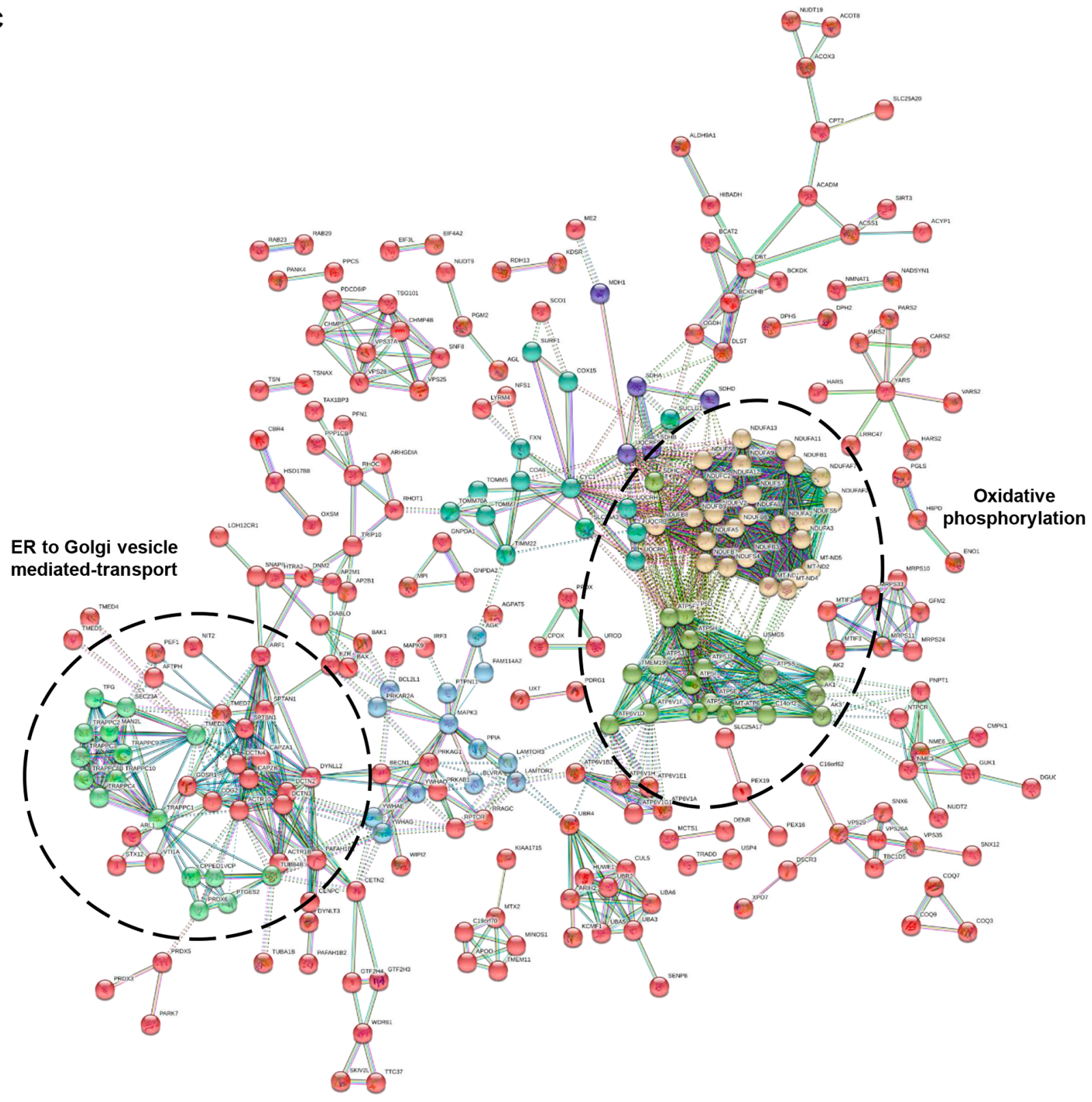

Figure 2. Coregulation analysis of human PITHD1. (A) Coregulation map of human PITHD1. The global coregulation map of ProteomeHD (www. proteomeHD.net $)^{45}$ is shown $(n=5013$ proteins). Purple dot corresponds to PITHD1, whereas green dots correspond to multiple proteins that tend to coregulate with PITHD1 across more than 290 biological perturbations. Distances between proteins indicate how similar their expression patterns are. (B) Top enriched ontology clusters across PITHD1 coregulated proteome by Metascape. (C) Protein interactome network for PITHD1 coregulated proteome. Network analysis was performed submitting the corresponding protein IDs to the STRING (Search Tool for the Retrieval of 
Figure 2. continued

Interacting Genes) software (v.10.5) (http://stringdb.org/). To minimize false positives as well as false negatives, only interactions tagged as "highest confidence" (>0.9) in STRING database were considered. K means clustering was applied (number of clusters: 6).

and detected by a Chemidoc MP Imaging System (Bio-Rad). Equal loading of the gels was assessed using Stain-free imaging technology. Thus, protein normalization was performed by measuring total protein directly on the gels used for Western blotting. After densitometric analyses (Image Lab Software Version 5.2; Bio-Rad), optical density values were expressed as arbitrary units and normalized to total protein levels.

\section{RESULTS AND DISCUSSION}

Enlightenment of the Dark Proteome: Focus on Human Olfactory Areas

Due to the relevance of the smell sense in neurodegeneration together with the dispersed information about the olfactory expression of the dark proteome, we have performed an exploratory analysis to check the presence of dark proteins in previous published data sets derived from human $\mathrm{OB}$ and cleft mucus. ${ }^{15,16,48,49}$ As shown in Figure 1A, $14 \%$ of the dark proteome has been previously detected in these specific olfactory areas (235 and 37 proteins in human $O B$ and cleft mucus respectively). Moreover, a small subset of dark proteins have been considered highly enriched transcripts in specific cell populations of the murine brain: ${ }^{50}$ KCTD4 in oligodendrocytes, GSE1 and PRR12 in neurons, ARMCX4, MROH1, and ZC2HC1A in microglia and LUZP2, CASKIN2 in astrocytes (Figure 1B). Cluster-enriched genes in specific OB cell layers have been recently detected. ${ }^{51}$ Our analysis has revealed that part of the dark proteome corresponds to highly expressed genes in mitral/tufted cell layer (FAM234B, PRNP, FAM171B, UBN2, C5MD2, LHFPL3, FAM184A, TTC14, FAM193B), olfactory sensory neurons (WDR89), periglomerular cell layer ( $S Y N$ DIG1L, PCP4L1, FAM49A), granular cell layer (TMEM191C, UBL3, FAM163B, CTXN3, POLR2M, UBALD2, RPRML, TTC9B, FAM81A, TMEM243, RSRP1, MRFAP1), and external plexiform layer (TMEM130) (Figure 1C). On the other hand, combining the information stored in three repositories containing the largest number of synapse specific proteins (G2Cdb, Synaptome DB, and SynsysNet), ${ }^{52-54}$ we have observed that $2 \%$ of the dark proteome ( 38 proteins) is part of synaptic terminals (Figure 1D). Recent studies point out that the proteome composition of neuropathological aggregates may differentiate specific pathological entities from the same disease spectrum. ${ }^{55}$ We wanted to know whether dark proteins have been experimentally characterized as interactors of neuropathological substrates. On the basis of the curated interactomic information present in the BioGrid repository, ${ }^{39}$ we interlocked the experimentally validated interactomes for amyloid precursor protein (APP; 2138 interactors), Tau protein (MAPT; 166 interactors), and alpha-synuclein (SNCA; 485 interactors) with the dark proteome. As shown in Figure 1E, 5\% of the dark proteome (102 proteins) has been demonstrated as physical interactor of APP. These compiled data indicate that multiple dark proteins are expressed in olfactory areas, tend to be localized at synaptic terminals, and may be involved in amyloidopathies such as $\mathrm{AD}$, opening doors to new research projects within the $\mathrm{B} / \mathrm{D}-\mathrm{HBPP}$ initiative.

\section{Functional Bioinformatic Screening for PITHD1}

Our group partially characterized the molecular alterations that accompany the OB neuropathological deposits in tardopathies, tauopathies, and synucleinopathies. ${ }^{15,16,28,56-63}$ Our olfactory proteotyping strategy revealed commonalities and differences across human $\mathrm{AD}$ and $\mathrm{PD},{ }^{15,16,63}$ suggesting that the shared $\mathrm{OB}$ proteome might be part of a common pathological disarrangement during the olfactory neurodegeneration in both phenotypes. Specifically, one of the protein components of this share OB proteome was the dark protein PITHD1, significantly altered in $\mathrm{AD}$ and $\mathrm{PD}$ in a neuropathological state-dependent manner. ${ }^{15,16}$ The PITHD1 gene is a highly conserved protein-coding gene located on chromosome 1 (1p36.11) (position 23778418 to 23788 232), that presents 325 orthologs according to NCBI database (Gene ID: 57095; NX_Q9GZP4, uPE1). Using a plethora of bioinformatic tools, we have observed that (i) PITHD1 tends to be localized in the nucleus, (ii) it is targeted by 8 phosphorylations, 5 ubiquitinations, 3 O-GalNAc sites, and 1 methylation site, (iii) its current protein interactome is mainly involved in transcription, signal transduction and chromatin organization (Supplementary Figure S1), (iv) PITHD1 is present in exosome/vesicles and in multiple human fluids like urine, milk, plasma, and cerebrospinal fluid (CSF), and (v) PITHD1 presents a low specificity across human cell lines and tissues, being ubiquitously expressed in the brain. On the basis of isolated findings generated by different unbiased highthroughput molecular approaches, PITHD1 mRNA/protein levels has been succinctly related to viral infections, ${ }^{64,65}$ oncologic treatments, ${ }^{66}$ and neurological syndromes such as neurocognitive decline, multiple sclerosis, and bipolar disorder. $^{67-69}$

Taking into account that protein expression profiling is superior to mRNA expression profiling for prediction of gene function, ${ }^{70,71}$ we applied a protein coexpression analysis to identify functional clues for the uncharacterized PITHD1 protein (Supplementary Table S2A). Using the coregulation map of the human proteome, ${ }^{45}$ we observed that PITHD1 tends to coregulate with mitochondrial protein components (Supplementary Table S2B) mainly involved in nucleotide metabolism, mitochondrial transport and autophagy (Supplementary Table S2C, Figure 2A,B). The interactome analysis of the PITHD1 coregulated proteome revealed several protein clusters with a direct role in oxidative phosphorylation and ER to Golgi vesiclemediated transport (Figure 2C). Even though most of PITHD1 experimentally demonstrated interactors correspond to nuclear proteins, these data suggest a potential role of PITHD1 out of the nucleus. Interestingly, a subset of PITHD1 coregulated proteins has been linked to neurological disorders such as $\mathrm{AD}$ and PD (Supplementary Table S2B). Moreover, part of OB deregulated proteome during $\mathrm{AD}$ and $\mathrm{PD}$ progression correspond to PITHD1 coregulated proteins ${ }^{15,16}$ (Supplementary Figure S2).

Subsequent analyses were performed to search functional relationships between PITHD1 and alpha-synuclein, tau, and beta-amyloid, well-known drivers for the pathological protein aggregates in a plethora of neurodegenerative diseases. ${ }^{72}$ On the 

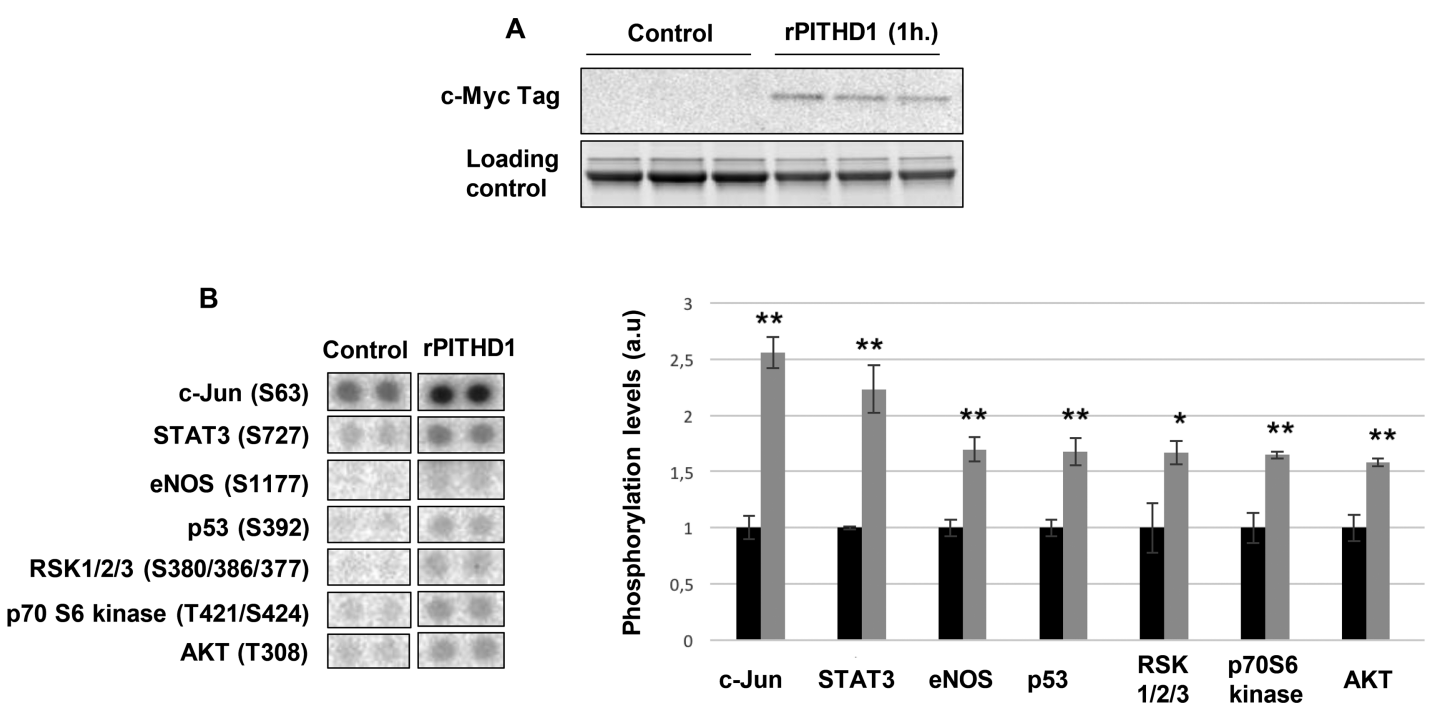

Figure 3. Targeted phosphoproteomic analysis of olfactory neuroepithelial cells upon PITHD1 stimulation. (A) rPITHD1 detection in the cell media of ON cells after $60 \mathrm{~min}$ of treatment. (B) rPITHD1 induces changes in the phosphorylation levels of specific transcription factors and kinases in ON cells $(60$ min treatment). Three independent experiments were performed. Data are presented as mean \pm SEM $* p<0.05$, ** $p<0.01$ vs unstimulated ON cells. Representative images of phosphokinase arrays are shown.

basis of the molecular information present in the BioGrid repository $^{39}$ only ANKRD39 (uPE1 protein according to NeXtProt 2020-01-17 release) was common between PITHD1 coregulated proteome and APP interactome, indicating that, based on the current knowledge, there is no a direct association between PITHD1 and the substrates of neuropathological aggregates at protein level.

\section{PITHD1 Early Alters the Olfactory Neuroepithelial} Phosphoproteome

A thorough scan and survey of the published high throughput proteomic studies in olfaction-related areas has revealed that PITHD1 has not been detected in olfactory sensory cilia, nasal mucous, and nasal lavage fluid. ${ }^{49,73,74}$ However, PITHD1 was identified in human olfactory neuroepithelium (ON), ${ }^{75}$ a peripheral tissue with a high neurogenesis capacity ${ }^{76}$ responsible for the initial interaction between the aromatic molecules and the olfactory sensory neurons (OSNs). This biological material is frequently used as a surrogate of central nervous system (CNS) function. ${ }^{77-79}$ Moreover, PITHD1 has been previously detected in human CSF. ${ }^{80,81}$ An olfactory CSF circuit exits through the olfactory system, running along the lateral olfactory stria, through the olfactory trigone, and down the olfactory tract (OT) to the olfactory bulb (OB), where CSF wriggles out through the cribriform plate to the nasal mucosa. ${ }^{82}$ With the aim to decipher the role of PITHD1 in the olfactory system, and mimicking the effects of exogenous PITHD1 within ON, subsequent experiments were performed to characterize the effects of human ON cells upon recombinant PITHD1 (rPITHD1) stimulation. First, we confirmed the purity of the recombinant protein as well as the presence of the full sequence of rPITHD 1 by double Western blotting against the $\mathrm{N}$ - and Cterminal tags and mass spectrometry (Supplementary Figure $S 3 A, B)$. Then, we verified that the presence of FBS in the cell media does not degrade the recombinant protein during $24 \mathrm{~h}$ of treatment (Supplementary Figure S3C). To identify signaling events induced soon after rPITHD1 stimulation, phosphokinase arrays were performed $60 \mathrm{~min}$ post-treatment. As shown in Figure 3, a significant induction in the activation state of some transcription factors like c-Jun, STAT3, as well as eNOS, RSK1/
2/3, p70 S6 kinase, and AKT was observed in human ON cells. eNOS, STAT3, and c-Jun have been previously related to odorant adaptation, ${ }^{83}$ OSN maturation and death. ${ }^{84,85}$ All these evidence together with the activation of kinases involved in cell survival such as RSK, p70 S6, and AKT point out that PITHD1 is able to interfere with the proliferative and differentiation state of the ON.

PITHD1 Reduces Proliferation and Triggers a Pro-inflammatory Phenotype in Olfactory Neuroepithelial Cells

Subsequent experiments were performed to analyze the effect of PITHD1 on cell proliferation. As shown in Figure 4A, PITHD1 induces a growth inhibition in $\mathrm{ON}$ cells, displaying a reduction on cell viability $24 \mathrm{~h}$ poststimulation. To characterize in detail the modulation of ON homeostasis by PITHD1 at intracellular level, a multiplex isobaric tagging approach (TMT) coupled to TIMS-TOF mass spectrometry was used (Supplementary Table S3). Specific markers of OSNs like $\beta$ III-tubulin (TUBB3), microtubule-associated protein $1 \mathrm{~B}(M A P 1 B)$ and ubiquitin carboxyl-terminal hydrolase isozyme L1 (UCHL1) were detected in ON cells by mass spectrometry (Supplementary Table S3). However, protein expression of neuronal precursor or olfactory epithelial stem cell markers ${ }^{77}$ were not observed in our ON cultured cells. The alteration in the proliferation rate was accompanied by a slight modulation of the $\mathrm{ON}$ intracellular proteome at $24 \mathrm{~h}$ post-treatment (3626 quantified proteins with at least 2 unique peptides). This modulation was reflected by the alteration of 51 proteins in rPITHD1-treated cells compared to untreated ON cells (20 down-regulated and 31 up-regulated proteins) (Supplementary Table S4) mainly located at cytoplasmic, nuclear and membrane-bounded organelle level. From a functional point of view, the differential protein subset was involved in the establishment of the endothelial barrier, signaling by interleukins, JAK-STAT pathway, regulation of neural precursor cell proliferation, axon guidance, and respiratory electron transport among others (Figure 4B, Supplementary Table S5). To complement the intracellular proteostatic imbalance induced by rPITHD1 in ON cells, we partially analyzed the secretome by protein arrays. Among the 80 
A

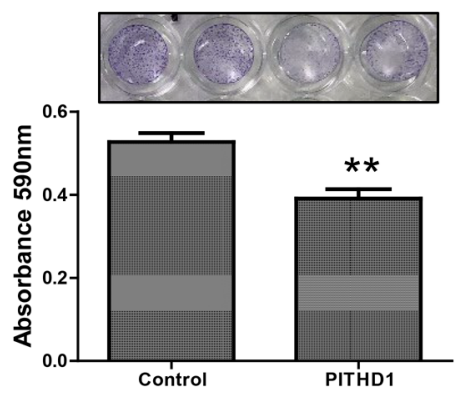

B

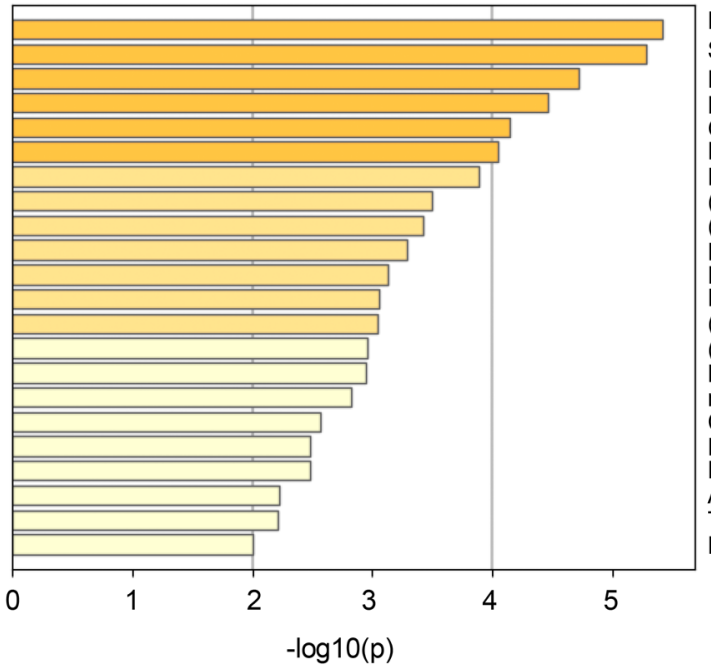

Establishment of endothelial barrier Signaling by interleukins Regulation of leukocyte mediated cytotoxicity Nectin pathway

Gene/Protein expression by JAK-STAT signaling after IL-12 stimulation Protein refolding

Extracellular matrix organization

$(+)$ Regulation of endocytosis

$(+)$ Regulation of endocytosis
$(+)$ Regulation of organelle organization

Regulation of GTPase activity

Huntington's disease

Regulation of neural precursor cell proliferation

(-) regulation of protein modification

(+) regulation of cellular component biogenesis

Maintenance of location in cell

ncRNA transcription

Cellular response to glucose

Regulation of RNA splicing

Regulation of JAK-STAT cascade

Axon guidance

TCA cycle and respiratory electron transport

Regulation of viral process

C
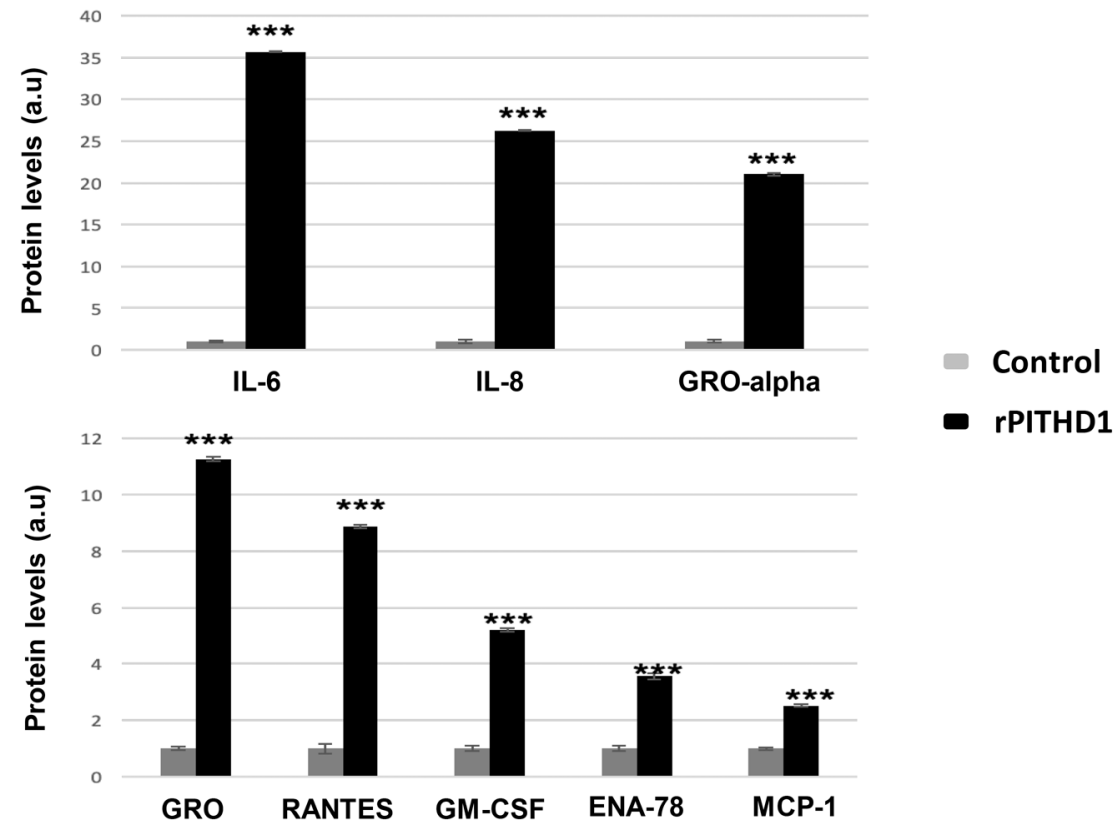

Figure 4. (A) Effect of PITHD1 in the proliferative capacity of ON cells. A significant reduction in cell survival was observed in PITHD1-treated ON cells $(24 \mathrm{~h})$ by crystal violet assay. Data are the mean \pm SEM from four independent experiments $(* * p<0.01$ vs unstimulated ON cells) (left). Western blotting against poly-His tag in the cell media at $24 \mathrm{~h}$ poststimulation (right). (B) Enriched ontology clusters across PITHD1-modulated proteome at $24 \mathrm{~h}$. This analysis was made using Metascape. (C) rPITHD1 induces changes in the extracellular cytokine profiling of ON cells. Eighty cytokines/ growth factors were monitored in the cell media of nontreated ON cells and rPITHD1-treated ON cells $(24 \mathrm{~h})$ using a dot-blot protein array method. Three independent experiments were performed. Data are presented as mean \pm SEM $* * * p<0.001$ vs nontreated ON cells.

secreted cell-cell signaling molecules analyzed, 7 were significantly increased upon PITHD1 treatment at $24 \mathrm{~h}$ (Figure 4C). Specifically, PITHD1 stimulation induced the production and secretion of multitasking cytokines such as IL-6 and IL-8 and chemokines like GRO-alpha, RANTES, ENA-78 (epithelial- cell-derived neutrophil attractant 78) and MCP-1, indicating that exogenous PITHD1 triggers a pro-inflammatory phenotype in ON cells. IL-6 is considered the cytokine most sensitive to OSN injuries, ${ }^{86,87}$ having inhibitory effects on neural stem cell differentiation $^{88}$ and being associated with ON atrophy and loss 
A
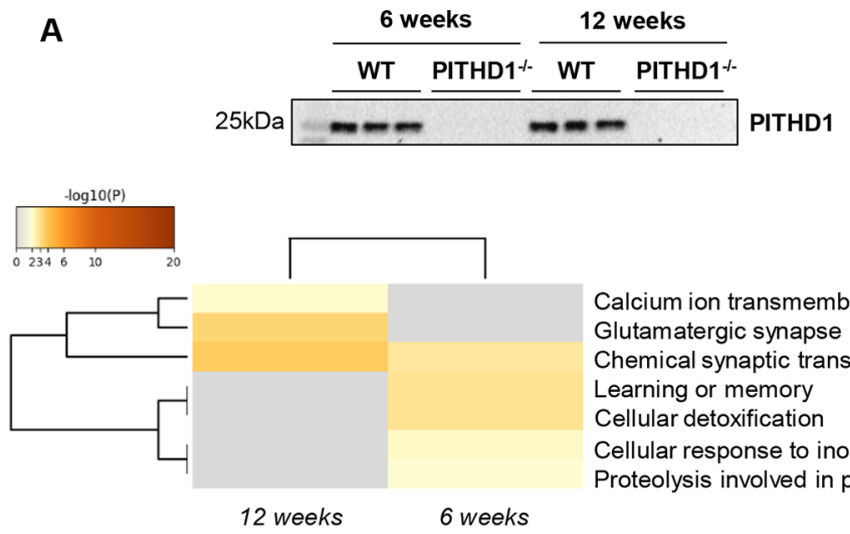

Calcium ion transmembrane transport Glutamatergic synapse Chemical synaptic transmission Learning or memory Cellular detoxification

Cellular response to inorganic substance Proteolysis involved in protein catabolism
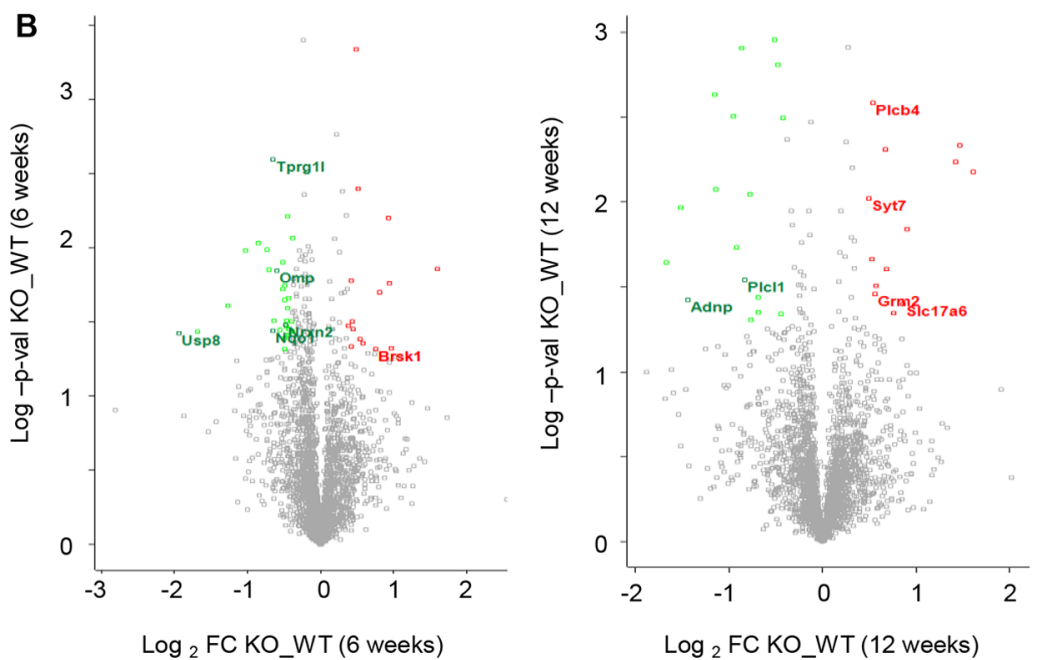

Figure 5. Synaptic transmission changes in the OB by PITHD1 deficiency. (A) Immunoblot analysis of PITHD1 protein in OB isolated from WT and PITHD $1^{-/}$mice. Equal loading of the gel was assessed by stain-free digitalization. (B) Functional clustering of OB differentially expressed proteins in $\mathrm{PITHD}^{-/-}$mice respect to WT animals (6-week and 12-week-old mice; $n=3 /$ group). (C) Volcano plot analysis of OB proteomes isolated from WT and PITHD $1^{-/-}$mice. Deregulated synaptic proteins are highlighted.

of OSNs. ${ }^{89}$ These inflammation-like features together with hallmarks of aged olfactory mucosa ${ }^{90}$ such as the alteration in the proliferation rate and extracellular matrix remodelling (upregulation of ICAM1, MMP1, NFKB2, PTX3, ANTXR1), suggest that PITHD1 may contribute to olfactory impairment during aging. Although our study has uncovered some intricacies about the role of PITHD1 in ON cells, there are potential limitations of our study that warrant discussion. The use of E. coli expressed-rPITHD1 unlikely maintains its tangled PTM profile, so additional studies using different expression systems and mutants will be needed to fully understand the specific role of each PTM on the PITHD1 functionality at olfactory level.

Early and Time-Dependent Molecular Derangements in Synaptic Transmission in the Olfactory Bulb of PITHD1 ${ }^{-/-}$ Mice

To examine the functionality of PITHD1 on the olfactory molecular homeostasis in vivo, we applied olfactory proteomics in 6-week and 3-month-old PITHD $1^{-/-}$mice. To analyze the potential differences in olfactory molecular expression profiles, OB specimens for each experimental group (PITHD1 $1^{-/-}$and WT mice) were subjected to SWATH-MS. From 2806 quantified proteins, the expression levels of 46 proteins were found to be significantly different between 6-week-old WT and PITHD ${ }^{-/-}$mice (31 down- and 15 up-regulated proteins with respect to WT mice), and 30 differentially expressed proteins were detected at 3 months of age ( 17 down- and 13 up-regulated proteins with respect to WT animals) (Supplementary Table S6). Functional analysis showed that part of the differential expressed proteins are involved in synaptic transmission (NQO1, GRM2, OMP, PLCB4, PLCL1, SYT7, USP8, NRXN2, ADNP, SLC17A6, BRSK1, TPRG1L), detoxification (NQO1, GSTM1, GSTZ1, PRXL2B, RHOB, USP8, CMBL, GATM, CARNS1), as well as in cognitive functions such as learning or memory (GATM, NRXN2, ADNP, UBA6, BRSK1) (Figure 5). These data point out that PITHD1 plays a role in olfactory trans-synaptic signaling in vivo.

Olfactory PITHD1 Expression in Aging and Neurodegeneration

Bearing in mind that our previous olfactory proteotyping applied in $\mathrm{AD}$ and $\mathrm{PD}^{63}$ did not distinguish between the numerous cell types coexisting in the $\mathrm{OB}$ region, immunohistochemical analyses were performed to map PITHD1 protein expression in mouse OB.

As shown in Figure 6, PITHD1 is detected in the glomerular cell layer, external plexiform layer, mitral cell layer, internal plexiform layer, and granular cell layer. Interestingly, PITHD1 is not exclusive to the nuclear part, being highly expressed at dendritic connections and across the neuropil. This protein profile across all $\mathrm{OB}$ cell layers is in accordance with previous $\mathrm{OB}$ single-cell RNA-seq outputs. ${ }^{51}$ It is well-known that the greatest known risk factor for the development of most of neurodegenerative diseases is aging. Moreover, age-related decline in 

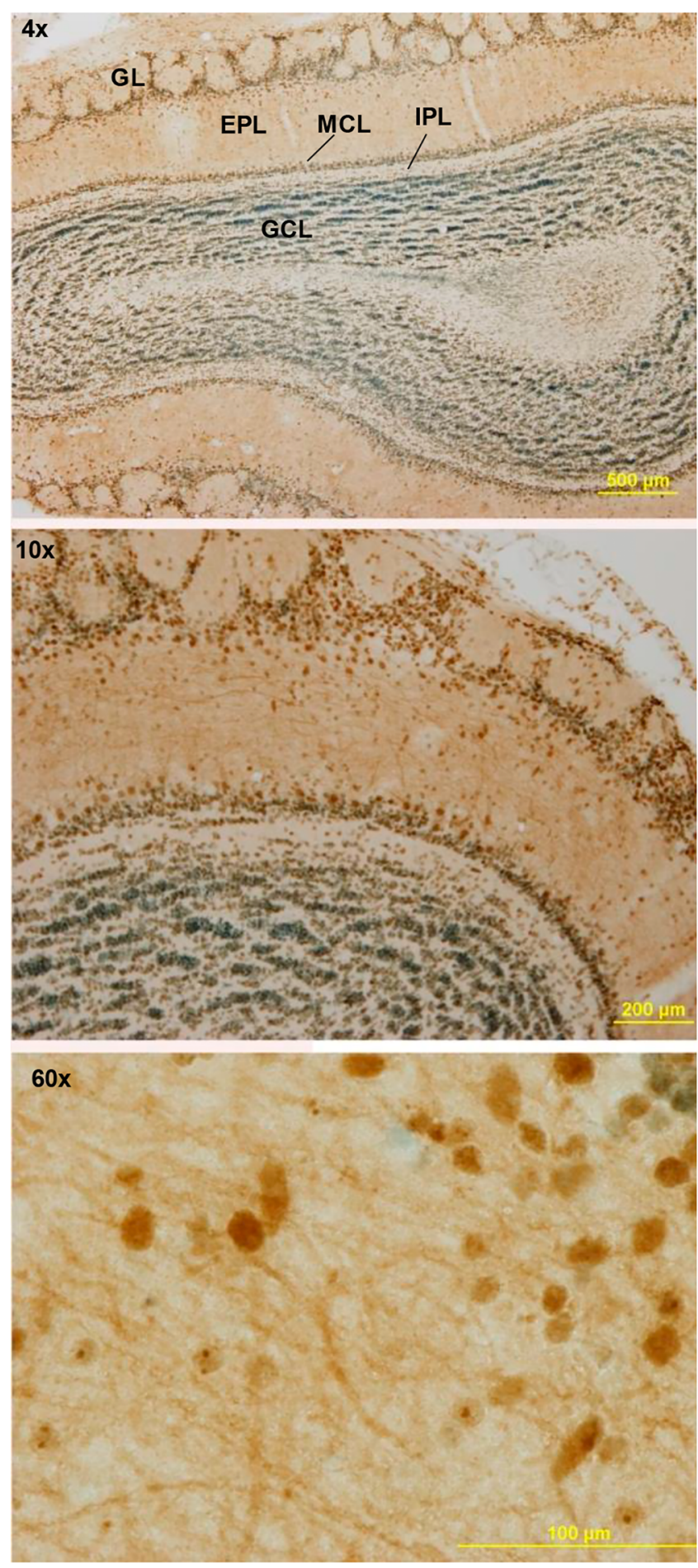

Figure 6. Immunohistochemical localization of PITHD1 in normal mouse OB. Representative immunohistochemical staining pattern of PITHD1 across OB cell layers (4-10X) (upper and middle) (GL: glomerular cell layer; EPL: external plexiform layer; MCL: mitral cell layer; IPL: internal plexiform layer; GCL: granular cell layer). Detail of PITHD1 expression in the nucleus and olfactory axons $(60 \times)$ (lower).

olfactory function is very common in the older population. ${ }^{91} \mathrm{On}$ the basis of this relation, we have observed that OB PITHD1 expression increases with age in wild-type (WT) mice (Figure 7A). However, OB PITHD1 levels are down-regulated in $\mathrm{Tg} 2576 \mathrm{AD}$ mice at the age of 18 months (Figure $7 \mathrm{~A}$ ), when transgenic mice show a robust pathology based on beta-amyloid plaques and behavior impairment. ${ }^{28}$ According to OB transcriptomic data obtained in aged $\mathrm{Tg} 2576$ mice, ${ }^{62}$ the drop in OB PITHD1 protein levels is not explained by transcriptional changes, indicating possible fluctuations in the protein degradation rate when $\mathrm{AD}$ pathology is well-established in $\mathrm{Tg} 2576$ mice. The apparent discrepancy in the regulation of $\mathrm{OB}$ PITHD1 levels between human $\mathrm{AD}$ and transgenic mice is not an unexpected observation, because the $\mathrm{AD}$ progression in amyloidogenic $\mathrm{AD}$ models is reminiscent of, but not identical with sporadic human $\mathrm{AD}$. This may be partially explained by species- and stage-dependent inflammatory mechanisms, ${ }^{92,93}$ differences in molecular events associated with $\beta$-amyloidogenesis, and the lack of intraneuronal neurofibrillary tangles.

Taking into account that complementary analysis of functionally interconnected areas may provide clues regarding the olfactory neurodegenerative process, we also focused our attention on the human olfactory tract (OT). The OT is constituted by the axons coming from the mitral and tufted neurons, that extend from the OB to the olfactory cortex. A significant degeneration of axons has been detected in the OT from $\mathrm{AD}$ subjects, ${ }^{94}$ correlating with the development of dementia. ${ }^{95}$ On the other hand, atrophy and changes in the structural integrity of OT have been also observed in PD subjects with respect to controls. ${ }^{96}$ Subsequent experiments were performed to characterize PITHD1 protein expression in OTs derived from $\mathrm{AD}$ and $\mathrm{PD}$ subjects. In accordance with previous data obtained at the level of the OB, ${ }^{16}$ OT PITHD1 expression was significantly higher in $\mathrm{AD}$ with respect to controls (Figure 7B). Interestingly, no changes were observed in OTs derived from the PD population (Figure $7 \mathrm{~B}$ ). Although axonal degeneration in OTs is a common feature between both phenotypes, our data point out that the role of PITHD1 in olfactory neurodegeneration is disease-dependent. We wanted to know whether olfactory PITHD1 is also modulated in additional neurological syndromes with different sensitivity to olfactory dysfunction. Together with $\mathrm{AD}$ and $\mathrm{PD}, \mathrm{DLB}$ and mixed dementia (where $\mathrm{AD}$ coexists with vascular pathology) are in the group of neurological disorders with severe smell impairment, whereas olfactory dysfunction occurs to a lesser extent or is absent in ALS and PSP. ${ }^{97}$ For that, Western blot analyses were performed in dementia with Lewy bodies (DLB; $n$ = 18), mixed dementia (Dmix; $n=7$ ), amyotrophic lateral sclerosis (ALS; $n=12$ ), and progressive supranuclear palsy (PSP; $n=10)$ cases and compared to control subjects $(n=8)$. As shown in Figure 7C, PITHD1 protein levels in OB and OT were unchanged across all neurological syndromes tested, suggesting that OT PITHD1 is specifically upregulated in human AD.

\section{CONCLUSION}

The smell sense is a tangled sensory system where electrobiochemical events trigger the conversion of the molecular information on odorants into odor sensation. Although phylogenetically ancient, the olfactory system has received less attention than other sensorial systems and this partially explains why many dark proteins expressed at the olfactory level are still uncharacterized (Supplementary Table S7). In fact, the functional proteomic characterization of olfactory receptors is a continual challenge, ${ }^{98}$ hampering the full elucidation of the pathways for the transmission of olfactory signaling ${ }^{99}$ as well as the function of their ectopic expression. ${ }^{100}$ Since olfactory dysfunction is considered an early prodromal event in neurodegenerative diseases, we have investigated the global expression of dark proteins in human olfactory structures. 
A
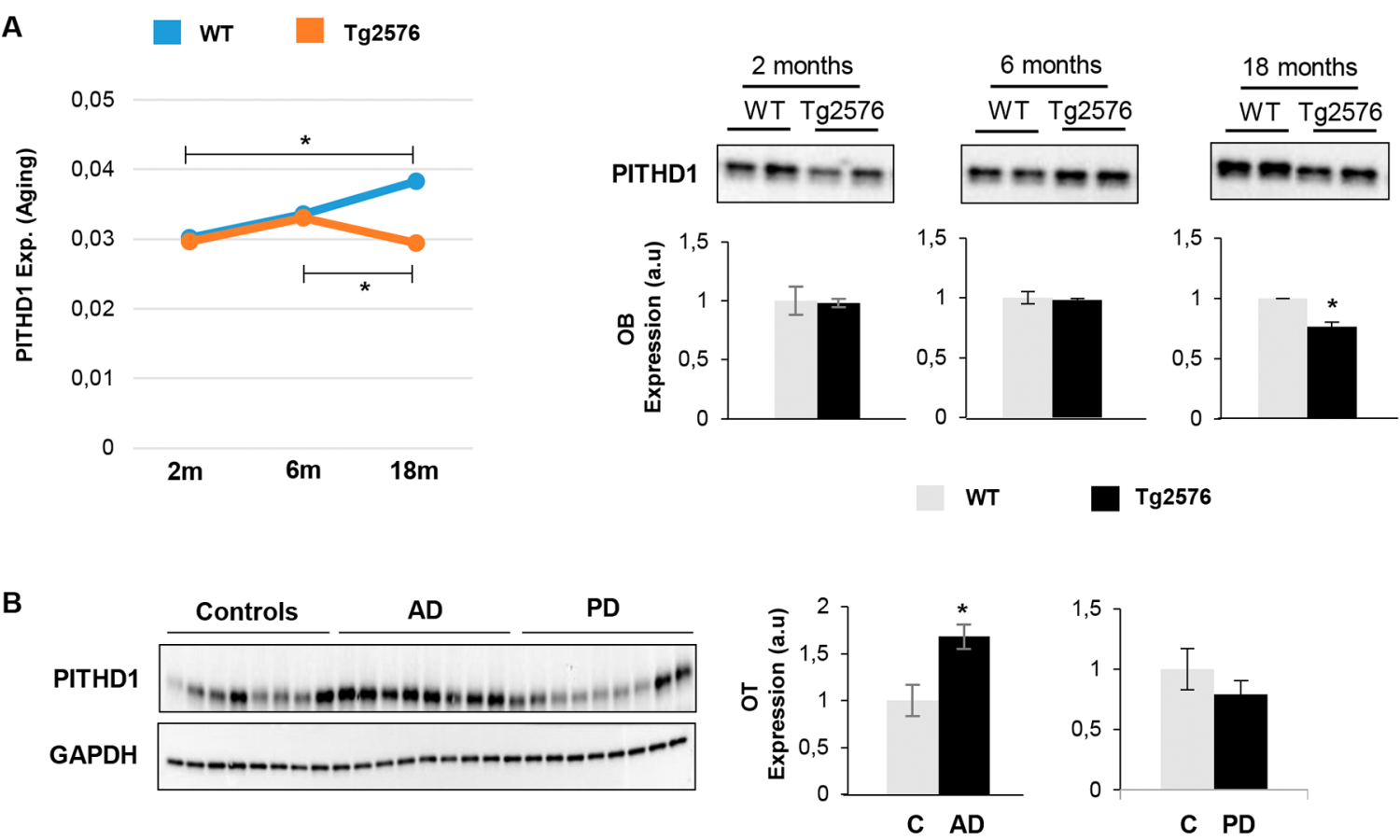

Tg2576

C
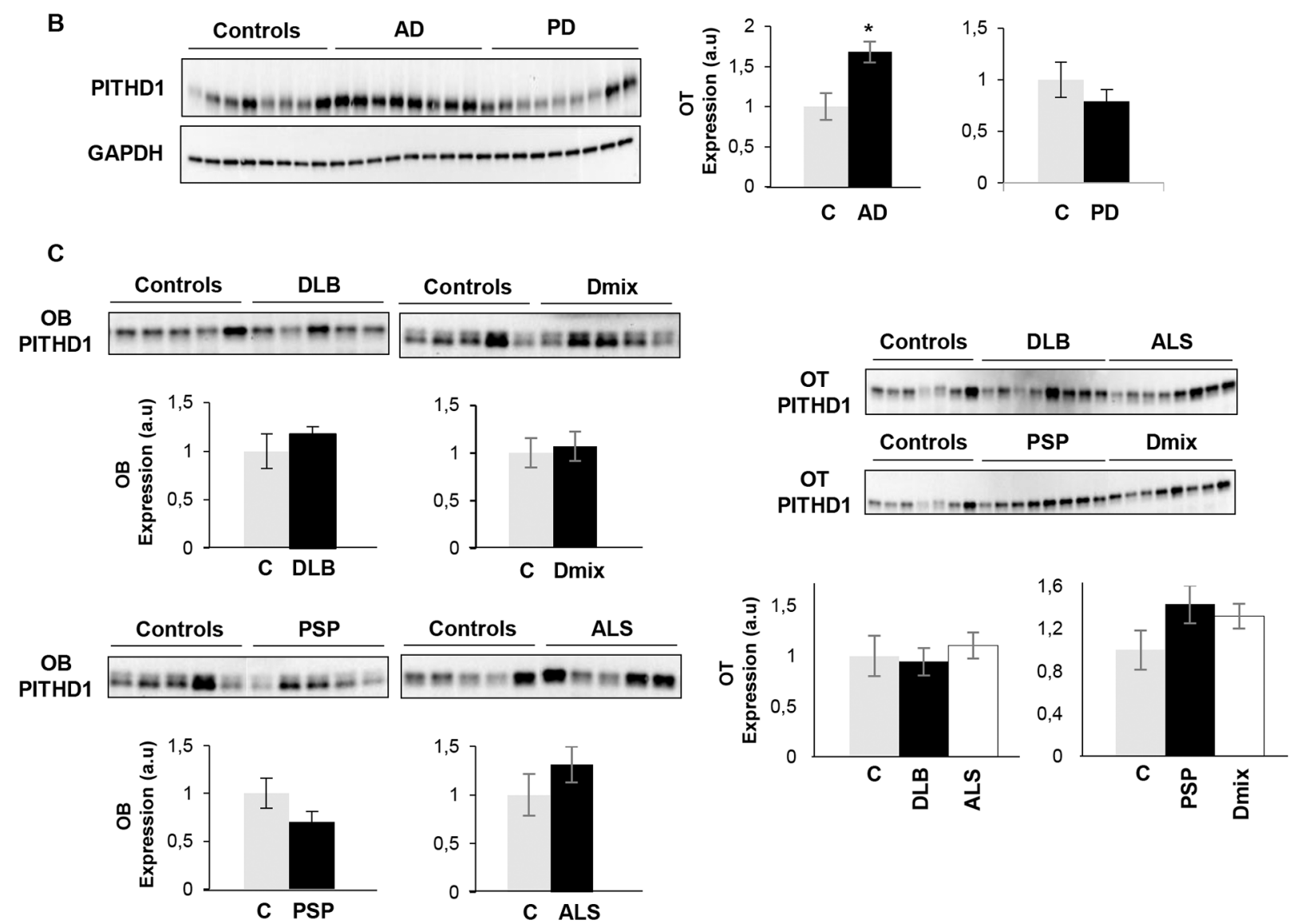

Figure 7. PITHD1 expression at the level of the OB and OT across neurological disorders. (A) Time-dependent evolution of the OB Pithd1 in WT and Tg2576 mice (right panels). Left graph represents the OB Pithd1 expression during the aging process in WT and Tg2576 mice (2-, 6-, and 18-monthold; $n=3$ per group). In all cases, Pithd1 expression was monitored by Western blotting. Equal loading of the gels was assessed by stain-free digitalization. Panels show histograms of band densities. Data are presented as mean \pm standard error of the mean $($ SEM). $(* P<0.05)$. (B) Western blotting analysis of OT PITHD1 in human AD and PD phenotypes. Equal loading of the gels was assessed by GAPDH levels. Panels show histograms of band densities. Data are presented as mean \pm standard error of the mean $(S E M) .(* P<0.05)$. (C) Western blotting analysis of OB (left panels) and OT PITHD1 (right panel) in human dementia with Lewy bodies (DLB), mixed dementia (Dmix), progressive supranuclear palsy (PSP) and amyotrophic lateral sclerosis (ALS). Equal loading of the gels was assessed by stain-free digitalization. Panels show histograms of band densities. Data are presented as mean \pm standard error of the mean (SEM). $\left({ }^{*} P<0.05\right)$. Full-length blots/gels are presented in Supporting Information.

Different bioinformatic workflows have been used to reveal functional features of poorly annotated human proteins. Zhang et al. developed a computational approach that generates protein structure predictions using I-TASSER, inferring GO functional clues for the Chromosome $17 \mathrm{uPE} 1$ proteome from functional templates recognized by COFACTOR. ${ }^{101}$ Using immunohistochemistry analysis and multiomic expression data sets derived from the testis, Melaine et al. localized multiple missing proteins and partially deciphered the functional role of specific dark proteins. ${ }^{102}$ On the basis of data-mining approaches across publicly available resources, complementary strategies have been postulated to greatly facilitate the experimental designs on dark proteins. ${ }^{103,104}$ In this work, we have revealed novel functional features of PITH domain-containing protein 1 


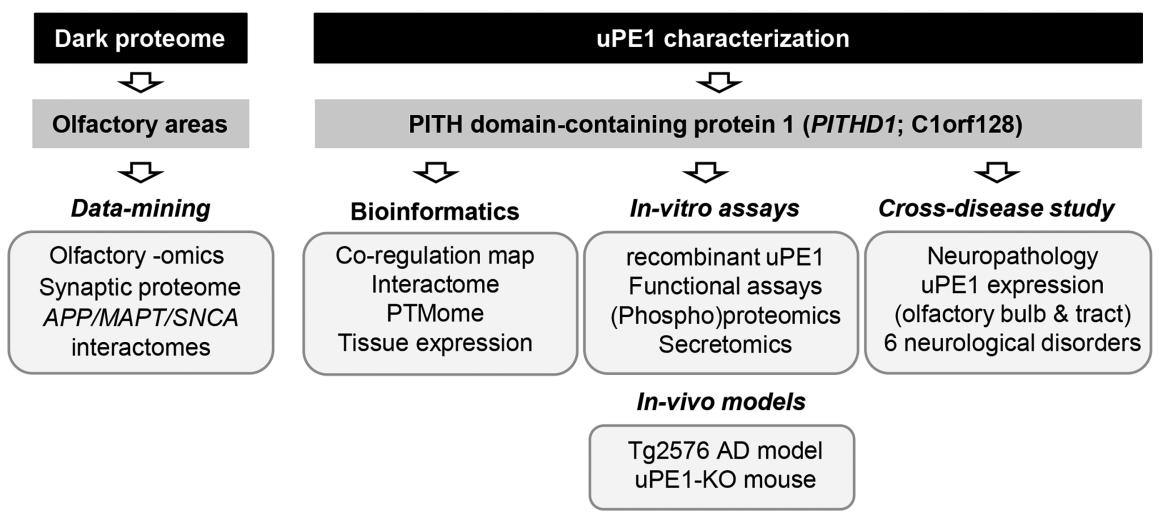

Figure 8. Experimental workflow used for the functional characterization of the PITHD1.

(PITHD1; C1orf128) using an experimental workflow based on bioinformatics, proteomics, in vitro and in vivo studies (using transgenic $\mathrm{AD}$ mouse model and PITHD1 $1^{-/-}$mouse), human clinico-neuropathological samples and immunological detections (Figure 8).

In particular, we report that (i) PITHD1 is localized across all OB cell layers, being highly expressed at nuclear and neuropil level; (ii) PITHD1 plays a role in trans-synaptic signaling in vivo; (iii) OB PITHD1 levels increase with age in mice; (iv) $\mathrm{OB}$ PITHD1 is compromised at late stages in Tg2576 AD mice; (v) OT PITHD1 is a differential feature between human $\mathrm{AD}$ and PD; (vi) PITHD1 specifically modulates signaling routes in ON cells and (vii) PITHD1 interferes with the proliferation rate of $\mathrm{ON}$ cells, inducing proteostatic changes and promoting a proinflammatory phenotype. We hope that our work will significantly aid the further characterization of additional dark proteins in the olfactory system, contributing to a better understanding of the molecular imbalances that occur in early phases of the neurodegenerative process.

\section{ASSOCIATED CONTENT}

\section{Supporting Information}

The Supporting Information is available free of charge at https://pubs.acs.org/doi/10.1021/acs.jproteome.0c00452.

Supplementary Figures S1-S4 (PDF)

Supplementary Table S1: Subjects included in this study (XLSX)

Supplementary Table S2: (A) Generation of the PITHD1 coregulation map using ProteomeHD; (B) GO Subcellular Components and KEGG pathways enriched among the PITHD1 coregulated proteome; (C) Functional annotation of the coregulated proteins by Metascape (XLSX)

Supplementary Table S3: Proteomics data using TMTTIMS-TOF MS (XLSX)

Supplementary Table S4: ON quantified proteome and differential expressed proteins upon PITHD1 stimulation (24 h post-treatment) (XLSX)

Supplementary Table S5: Functional analysis of PITHD1-modulated proteome in ON cells by Metascape (XLSX)

Supplementary Table S6: Quantitative olfactory proteomics in PITHD $1^{-/-}$mice and functional analysis (XLSX) Supplementary Table S7: Descriptive analysis of missing proteins and uncharacterized proteins previously observed at RNA or protein level in olfactory structures, OB cell layers, brain cell-types, neuropathological interactomes and synaptosomes (XLSX)

\section{AUTHOR INFORMATION}

\section{Corresponding Author}

Enrique Santamaría - Clinical Neuroproteomics Unit, Navarrabiomed, Complejo Hospitalario de Navarra (CHN) and Proteored-ISCIII, Proteomics Platform, Navarrabiomed, Complejo Hospitalario de Navarra (CHN), Universidad Pública de Navarra (UPNA), 31008 Pamplona, Spain; IdiSNA, Navarra Institute for Health Research, 31008 Pamplona, Spain; () orcid.org/0000-0001-8046-8102; Email: esantamma@navarra.es

\section{Authors}

Mercedes Lachén-Montes - Clinical Neuroproteomics Unit, Navarrabiomed, Complejo Hospitalario de Navarra (CHN) and Proteored-ISCIII, Proteomics Platform, Navarrabiomed, Complejo Hospitalario de Navarra (CHN), Universidad Pública de Navarra (UPNA), 31008 Pamplona, Spain; IdiSNA, Navarra Institute for Health Research, 31008 Pamplona, Spain

Naroa Mendizuri - Clinical Neuroproteomics Unit, Navarrabiomed, Complejo Hospitalario de Navarra (CHN) and Proteored-ISCIII, Proteomics Platform, Navarrabiomed, Complejo Hospitalario de Navarra (CHN), Universidad Pública de Navarra (UPNA), 31008 Pamplona, Spain; IdiSNA, Navarra Institute for Health Research, 31008 Pamplona, Spain

Karina Ausín - Clinical Neuroproteomics Unit, Navarrabiomed, Complejo Hospitalario de Navarra (CHN) and Proteored-ISCIII, Proteomics Platform, Navarrabiomed, Complejo Hospitalario de Navarra (CHN), Universidad Pública de Navarra (UPNA), 31008 Pamplona, Spain; IdiSNA, Navarra Institute for Health Research, 31008 Pamplona, Spain

Alberto Pérez-Mediavilla - IdiSNA, Navarra Institute for Health Research, 31008 Pamplona, Spain; Neurobiology of Alzheimer's Disease, Department of Biochemistry, Center for Applied Medical Research (CIMA), Neurosciences Division, University of Navarra, 31008 Pamplona, Spain

Mikel Azkargorta - Proteomics Platform, CIC bioGUNE, CIBERehd, ProteoRed-ISCIII, 48160 Derio, Spain

Ibon Iloro - Proteomics Platform, CIC bioGUNE, CIBERehd, ProteoRed-ISCIII, 48160 Derio, Spain 
Felix Elortza - Proteomics Platform, CIC bioGUNE, CIBERehd, ProteoRed-ISCIII, 48160 Derio, Spain

Hiroyuki Kondo - Division of Experimental Immunology, Institute of Advanced Medical Sciences, Tokushima University, Tokushima 770-8503, Japan

Izumi Ohigashi - Division of Experimental Immunology, Institute of Advanced Medical Sciences, Tokushima University, Tokushima 770-8503, Japan

Isidre Ferrer - Bellvitge Biomedical Research Institute (IDIBELL), 08908 Hospitalet de Llobregat, Spain; CIBERNED (Network Centre of Biomedical Research of Neurodegenerative Diseases), Institute of Health Carlos III, 28029 Madrid, Spain; Department of Pathology and Experimental Therapeutics and Institute of Neurosciences, University of Barcelona, 08908 Hospitalet de Llobregat, Spain

Rafael de la Torre - Integrative Pharmacology and Systems Neuroscience Research Group, Neurosciences Research Program, IMIM (Hospital del Mar Medical Research Institute), 08003 Barcelona, Spain; Department of Experimental and Health Sciences, Pompeu Fabra University (CEXS-UPF), 08002 Barcelona, Spain; School of Medicine, Universitat Autònoma de Barcelona, 08193 Cerdanyola del Vallès, Spain; CIBER de Fisiopatología de la Obesidad y Nutrición (CB06/03), CIBEROBN, 28029 Madrid, Spain

Patricia Robledo - Integrative Pharmacology and Systems Neuroscience Research Group, Neurosciences Research Program, IMIM (Hospital del Mar Medical Research Institute), 08003 Barcelona, Spain; Department of Experimental and Health Sciences, Pompeu Fabra University (CEXS-UPF), 08002 Barcelona, Spain

Joaquín Fernández-Irigoyen - Clinical Neuroproteomics Unit, Navarrabiomed, Complejo Hospitalario de Navarra (CHN) and Proteored-ISCIII, Proteomics Platform, Navarrabiomed, Complejo Hospitalario de Navarra (CHN), Universidad Pública de Navarra (UPNA), 31008 Pamplona, Spain; IdiSNA, Navarra Institute for Health Research, 31008 Pamplona, Spain

Complete contact information is available at:

https://pubs.acs.org/10.1021/acs.jproteome.0c00452

\section{Author Contributions}

${ }^{\dagger}$ JFI and ES share senior authorship

\section{Author Contributions}

Conceptualization and supervision, Enrique Santamaria. Formal analysis, Mercedes Lachén-Montes, Naroa Mendizuri. Funding acquisition, Enrique Santamaria, Joaquin Fernández-Irigoyen. Investigation, Mercedes Lachén-Montes, Naroa Mendizuri, Karina Ausin, Patricia Robledo, Hiroyuki Kondo, Izumi Ohigashi, Rafael de la Torre, Joaquín Fernández-Irigoyen, Enrique Santamaria. In vivo studies; Alberto Pérez-Mediavilla, Hiroyuki Kondo, Izumi Ohigashi. Neuropathological diagnosis, Isidre Ferrer. Methodology, Patricia Robledo, Rafael de la Torre, Joaquín Fernández-Irigoyen, Enrique Santamaria, Mikel Azkargorta, Ibon Iloro, Felix Elortza. Software, Enrique Santamaria, Joaquin Fernández-Irigoyen, Mikel Azkargorta, Ibon Iloro, Felix Elortza. Bioinformatics, Enrique Santamaria, Mercedes LachénMontes. Supervision, Enrique Santamaria. Writing original draft, Enrique Santamaria. All authors gave final approval of the manuscript and are accountable for all aspects of the work.

Notes

The authors declare no competing financial interest.
All MS raw data and search results files have been deposited to the ProteomeXchange Consortium (http://proteomecentral. proteomexchange.org) via the PRIDE partner repository with the data set identifiers PXD018784 and PXD021634.

\section{ACKNOWLEDGMENTS}

We are very grateful to the patients and relatives that generously donated the brain tissue for research purposes. We are indebted to the Neurological Tissue Bank of the Biobank from the Hospital Clinic-Institut d'Investigacions Biomédiques August Pi i Sunyer (IDIBAPS, Barcelona) and the Neurological Tissue Bank of HUB-ICO-IDIBELL (Barcelona, Spain) for sample and data procurement. Authors thank all of the PRIDE Team for helping with the mass spectrometric data deposit in ProteomeXChange/PRIDE. CIC bioGUNE is supported by Basque Department of Industry, Tourism and Trade (Etortek and Elkartek programs), the Innovation Technology Department of the Bizkaia County; The ProteoRed-ISCIII (Grant PRB3 IPT17/0019); CIBERehd Network and Severo Ochoa Grant (SEV-2016-0644). The Clinical Neuroproteomics Unit of Navarrabiomed is a member of the Global Consortium for Chemosensory Research (GCCR) and the Spanish Olfactory Network (ROE) (supported by grant RED2018-102662-T funded by Spanish Ministry of Science and Innovation). This project is part of the HUPO Brain Proteome Project, and these results are lined up with the Spanish Initiative on the Human Proteome Project (SpHPP). This work was funded by grants from the Spanish Ministry of Science Innovation and Universities (ref. PID2019-110356RB-I00 to JFI and ES) and Department of Economic and Business Development from Government of Navarra (ref. 0011-1411-2020-000028) to ES and from MEXT-JSPS $17 \mathrm{~K} 08884$ and Takeda Science Foundation to IO. The Proteomics Unit of Navarrabiomed is a member of Proteored (PRB3-ISCIII) and is supported by grant PT17/0019/009 to JFI, of the PE I+D+I 2013-2016 funded by ISCIII and FEDER. MLM was supported by a postdoctoral fellowship from the Public University of Navarra (UPNA).

\section{ABBREVIATIONS}

ON, olfactory neuroepithelium; OSN, olfactory sensory neuron; $\mathrm{OB}$, olfactory bulb; $\mathrm{AD}$, Alzheimer's disease; PD, Parkinson's disease, ALS, amyotrophic lateral sclerosis; PSP, progressive supranuclear palsy; DLB, dementia with Lewy bodies; PITHD1, PITH domain-containing protein 1 .

\section{REFERENCES}

(1) Omenn, G. S.; Lane, L.; Overall, C. M.; Corrales, F. J.; Schwenk, J. M.; Paik, Y. K.; Van Eyk, J. E.; Liu, S.; Pennington, S.; Snyder, M. P.; Baker, M. S.; Deutsch, E. W. Progress on Identifying and Characterizing the Human Proteome: 2019 Metrics from the HUPO Human Proteome Project. J. Proteome Res. 2019, 18 (12), 4098-4107.

(2) Paik, Y. K.; Omenn, G. S.; Uhlen, M.; Hanash, S.; Marko-Varga, G.; Aebersold, R.; Bairoch, A.; Yamamoto, T.; Legrain, P.; Lee, H. J.; Na, K.; Jeong, S. K.; He, F.; Binz, P. A.; Nishimura, T.; Keown, P.; Baker, M. S.; Yoo, J. S.; Garin, J.; Archakov, A.; Bergeron, J.; Salekdeh, G. H.; Hancock, W. S. Standard guidelines for the chromosome-centric human proteome project. J. Proteome Res. 2012, 11 (4), 2005-13.

(3) Paik, Y. K.; Jeong, S. K.; Omenn, G. S.; Uhlen, M.; Hanash, S.; Cho, S. Y.; Lee, H. J.; Na, K.; Choi, E. Y.; Yan, F.; Zhang, F.; Zhang, Y.; Snyder, M.; Cheng, Y.; Chen, R.; Marko-Varga, G.; Deutsch, E. W.; Kim, H.; Kwon, J. Y.; Aebersold, R.; Bairoch, A.; Taylor, A. D.; Kim, K. Y.; Lee, E. Y.; Hochstrasser, D.; Legrain, P.; Hancock, W. S. The 
Chromosome-Centric Human Proteome Project for cataloging proteins encoded in the genome. Nat. Biotechnol. 2012, 30 (3), 221-3. (4) Aebersold, R.; Bader, G. D.; Edwards, A. M.; van Eyk, J. E.; Kussmann, M.; Qin, J.; Omenn, G. S. The biology/disease-driven human proteome project (B/D-HPP): enabling protein research for the life sciences community. J. Proteome Res. 2013, 12 (1), 23-7.

(5) Paik, Y.-K.; Lane, L.; Kawamura, T.; Chen, Y.-J.; Cho, J.-Y.; LaBaer, J.; Yoo, J. S.; Domont, G.; Corrales, F.; Omenn, G. S.; Archakov, A.; Encarnacion-Guevara, S.; Lui, S.; Salekdeh, G. H.; Cho, J.-Y.; Kim, C.-Y.; Overall, C. M. Launching the C-HPP neXt-CP50 Pilot Project for Functional Characterization of Identified Proteins with No Known Function. J. Proteome Res. 2018, 17 (12), 4042-4050.

(6) Zahn-Zabal, M.; Michel, P. A.; Gateau, A.; Nikitin, F.; Schaeffer, M.; Audot, E.; Gaudet, P.; Duek, P. D.; Teixeira, D.; Rech de Laval, V.; Samarasinghe, K.; Bairoch, A.; Lane, L. The neXtProt knowledgebase in 2020: data, tools and usability improvements. Nucleic Acids Res. 2019, 48 (D1), D328-D334.

(7) Paik, Y. K.; Overall, C. M.; Corrales, F.; Deutsch, E. W.; Lane, L.; Omenn, G. S. Toward Completion of the Human Proteome Parts List: Progress Uncovering Proteins That Are Missing or Have Unknown Function and Developing Analytical Methods. J. Proteome Res. 2018, 17 (12), 4023-4030.

(8) Paik, Y. K.; Omenn, G. S.; Hancock, W. S.; Lane, L.; Overall, C. M. Advances in the Chromosome-Centric Human Proteome Project: looking to the future. Expert Rev. Proteomics 2017, 14 (12), 1059-1071.

(9) Fernandez-Irigoyen, J.; Corrales, F.; Santamaria, E. The Human Brain Proteome Project: Biological and Technological Challenges. Methods Mol. Biol. 2019, 2044, 3-23.

(10) Doty, R. L. Olfactory dysfunction in Parkinson disease. Nat. Rev. Neurol. 2012, 8 (6), 329-39.

(11) Burkard, T. R.; Planyavsky, M.; Kaupe, I.; Breitwieser, F. P.; Burckstummer, T.; Bennett, K. L.; Superti-Furga, G.; Colinge, J. Initial characterization of the human central proteome. BMC Syst. Biol. 2011, $5,17$.

(12) Lu, B.; Sun, X.; Chen, Y.; Jin, Q.; Liang, Q.; Liu, S.; Li, Y.; Zhou, Y.; Li, W.; Huang, Z. Novel function of PITH domain-containing 1 as an activator of internal ribosomal entry site to enhance RUNX1 expression and promote megakaryocyte differentiation. Cell. Mol. Life Sci. 2015, 72 (4), 821-32.

(13) Engqvist, H.; Parris, T. Z.; Kovacs, A.; Nemes, S.; Werner Ronnerman, E.; De Lara, S.; Biermann, J.; Sundfeldt, K.; Karlsson, P.; Helou, K. Immunohistochemical validation of COL3A1, GPR158 and PITHD1 as prognostic biomarkers in early-stage ovarian carcinomas. BMC Cancer 2019, 19 (1), 928.

(14) Kondo, H.; Matsumura, T.; Kaneko, M.; Inoue, K.; Kosako, H.; Ikawa, M.; Takahama, Y.; Ohigashi, I. PITHD1 is a proteasomeinteracting protein essential for male fertilization. J. Biol. Chem. 2020, 295 (6), 1658-1672.

(15) Lachen-Montes, M.; Gonzalez-Morales, A.; Iloro, I.; Elortza, F.; Ferrer, I.; Gveric, D.; Fernandez-Irigoyen, J.; Santamaria, E. Unveiling the olfactory proteostatic disarrangement in Parkinson's disease by proteome-wide profiling. Neurobiol. Aging 2019, 73, 123-134.

(16) Lachen-Montes, M.; Gonzalez-Morales, A.; Zelaya, M. V.; PerezValderrama, E.; Ausin, K.; Ferrer, I.; Fernandez-Irigoyen, J.; Santamaria, E. Olfactory bulb neuroproteomics reveals a chronological perturbation of survival routes and a disruption of prohibitin complex during Alzheimer's disease progression. Sci. Rep. 2017, 7 (1), 9115.

(17) Alafuzoff, I.; Arzberger, T.; Al-Sarraj, S.; Bodi, I.; Bogdanovic, N.; Braak, H.; Bugiani, O.; Del-Tredici, K.; Ferrer, I.; Gelpi, E.; Giaccone, G.; Graeber, M. B.; Ince, P.; Kamphorst, W.; King, A.; Korkolopoulou, P.; Kovacs, G. G.; Larionov, S.; Meyronet, D.; Monoranu, C.; Parchi, P.; Patsouris, E.; Roggendorf, W.; Seilhean, D.; Tagliavini, F.; Stadelmann, C.; Streichenberger, N.; Thal, D. R.; Wharton, S. B.; Kretzschmar, H. Staging of neurofibrillary pathology in Alzheimer's disease: a study of the Brain Net Europe Consortium. Brain Pathol. 2008, 18 (4), 484496.

(18) Montine, T. J.; Phelps, C. H.; Beach, T. G.; Bigio, E. H.; Cairns, N. J.; Dickson, D. W.; Duyckaerts, C.; Frosch, M. P.; Masliah, E.; Mirra, S. S.; Nelson, P. T.; Schneider, J. A.; Thal, D. R.; Trojanowski, J. Q.;
Vinters, H. V.; Hyman, B. T. National Institute on Aging-Alzheimer's Association guidelines for the neuropathologic assessment of Alzheimer's disease: a practical approach. Acta Neuropathol. 2012, $123(1), 1-11$.

(19) Thal, D. R.; Rub, U.; Orantes, M.; Braak, H. Phases of A betadeposition in the human brain and its relevance for the development of AD. Neurology 2002, 58 (12), 1791-800.

(20) Crary, J. F.; Trojanowski, J. Q.; Schneider, J. A.; Abisambra, J. F.; Abner, E. L.; Alafuzoff, I.; Arnold, S. E.; Attems, J.; Beach, T. G.; Bigio, E. H.; Cairns, N. J.; Dickson, D. W.; Gearing, M.; Grinberg, L. T.; Hof, P. R.; Hyman, B. T.; Jellinger, K.; Jicha, G. A.; Kovacs, G. G.; Knopman, D. S.; Kofler, J.; Kukull, W. A.; Mackenzie, I. R.; Masliah, E.; McKee, A.; Montine, T. J.; Murray, M. E.; Neltner, J. H.; Santa-Maria, I.; Seeley, W. W.; Serrano-Pozo, A.; Shelanski, M. L.; Stein, T.; Takao, M.; Thal, D. R.; Toledo, J. B.; Troncoso, J. C.; Vonsattel, J. P.; White, C. L., 3rd; Wisniewski, T.; Woltjer, R. L.; Yamada, M.; Nelson, P. T. Primary agerelated tauopathy (PART): a common pathology associated with human aging. Acta Neuropathol. 2014, 128 (6), 755-66.

(21) Alafuzoff, I.; Ince, P. G.; Arzberger, T.; Al-Sarraj, S.; Bell, J.; Bodi, I.; Bogdanovic, N.; Bugiani, O.; Ferrer, I.; Gelpi, E.; Gentleman, S.; Giaccone, G.; Ironside, J. W.; Kavantzas, N.; King, A.; Korkolopoulou, P.; Kovacs, G. G.; Meyronet, D.; Monoranu, C.; Parchi, P.; Parkkinen, L.; Patsouris, E.; Roggendorf, W.; Rozemuller, A.; Stadelmann-Nessler, C.; Streichenberger, N.; Thal, D. R.; Kretzschmar, H. Staging/typing of Lewy body related alpha-synuclein pathology: a study of the Brain Net Europe Consortium. Acta Neuropathol. 2009, 117 (6), 635-52.

(22) Roman, G. C.; Tatemichi, T. K.; Erkinjuntti, T.; Cummings, J. L.; Masdeu, J. C.; Garcia, J. H.; Amaducci, L.; Orgogozo, J. M.; Brun, A.; Hofman, A.; et al. Vascular dementia: diagnostic criteria for research studies. Report of the NINDS-AIREN International Workshop. Neurology 1993, 43 (2), 250-60.

(23) Litvan, I.; Hauw, J. J.; Bartko, J. J.; Lantos, P. L.; Daniel, S. E.; Horoupian, D. S.; McKee, A.; Dickson, D.; Bancher, C.; Tabaton, M.; Jellinger, K.; Anderson, D. W. Validity and reliability of the preliminary NINDS neuropathologic criteria for progressive supranuclear palsy and related disorders. J. Neuropathol. Exp. Neurol. 1996, 55 (1), 97-105.

(24) Cairns, N. J.; Bigio, E. H.; Mackenzie, I. R.; Neumann, M.; Lee, V. M.; Hatanpaa, K. J.; White, C. L., 3rd; Schneider, J. A.; Grinberg, L. T.; Halliday, G.; Duyckaerts, C.; Lowe, J. S.; Holm, I. E.; Tolnay, M.; Okamoto, K.; Yokoo, H.; Murayama, S.; Woulfe, J.; Munoz, D. G.; Dickson, D. W.; Ince, P. G.; Trojanowski, J. Q.; Mann, D. M. Neuropathologic diagnostic and nosologic criteria for frontotemporal lobar degeneration: consensus of the Consortium for Frontotemporal Lobar Degeneration. Acta Neuropathol. 2007, 114 (1), 5-22.

(25) Braak, H.; Alafuzoff, I.; Arzberger, T.; Kretzschmar, H.; Del Tredici, K. Staging of Alzheimer disease-associated neurofibrillary pathology using paraffin sections and immunocytochemistry. Acta Neuropathol. 2006, 112 (4), 389-404.

(26) Hsiao, K.; Chapman, P.; Nilsen, S.; Eckman, C.; Harigaya, Y.; Younkin, S.; Yang, F.; Cole, G. Correlative memory deficits, Abeta elevation, and amyloid plaques in transgenic mice. Science 1996, 274 (5284), 99-102.

(27) Cuadrado-Tejedor, M.; Garcia-Osta, A. Current animal models of Alzheimer's disease: challenges in translational research. Front. Neurol. 2014, 5, 182.

(28) Lachen-Montes, M.; Gonzalez-Morales, A.; Palomino, M.; Ausin, K.; Gomez-Ochoa, M.; Zelaya, M. V.; Ferrer, I.; Perez-Mediavilla, A.; Fernandez-Irigoyen, J.; Santamaria, E. Early-Onset Molecular Derangements in the Olfactory Bulb of Tg2576 Mice: Novel Insights Into the Stress-Responsive Olfactory Kinase Dynamics in Alzheimer's Disease. Front. Aging Neurosci. 2019, 11, 141.

(29) Benitez-King, G.; Riquelme, A.; Ortiz-Lopez, L.; Berlanga, C.; Rodriguez-Verdugo, M. S.; Romo, F.; Calixto, E.; Solis-Chagoyan, H.; Jimenez, M.; Montano, L. M.; Ramirez-Rodriguez, G.; Morales-Mulia, S.; Dominguez-Alonso, A. A non-invasive method to isolate the neuronal linage from the nasal epithelium from schizophrenic and bipolar diseases. J. Neurosci. Methods 2011, 201 (1), 35-45.

(30) Galindo, L.; Moreno, E.; Lopez-Armenta, F.; Guinart, D.; Cuenca-Royo, A.; Izquierdo-Serra, M.; Xicota, L.; Fernandez, C.; 
Menoyo, E.; Fernandez-Fernandez, J. M.; Benitez-King, G.; Canela, E. I.; Casado, V.; Perez, V.; de la Torre, R.; Robledo, P. Cannabis Users Show Enhanced Expression of CB1-5HT2A Receptor Heteromers in Olfactory Neuroepithelium Cells. Mol. Neurobiol. 2018, 55 (8), 63476361.

(31) Zhang, J.; Xin, L.; Shan, B.; Chen, W.; Xie, M.; Yuen, D.; Zhang, W.; Zhang, Z.; Lajoie, G. A.; Ma, B. PEAKS DB: de novo sequencing assisted database search for sensitive and accurate peptide identification. Mol. Cell. Proteomics 2012, 11 (4), M111.010587.

(32) Shevchenko, A.; Tomas, H.; Havli, J.; Olsen, J. V.; Mann, M. Ingel digestion for mass spectrometric characterization of proteins and proteomes. Nat. Protoc. 2006, 1 (6), 2856-2860.

(33) Shilov, I. V.; Seymour, S. L.; Patel, A. A.; Loboda, A.; Tang, W. H.; Keating, S. P.; Hunter, C. L.; Nuwaysir, L. M.; Schaeffer, D. A. The Paragon Algorithm, a next generation search engine that uses sequence temperature values and feature probabilities to identify peptides from tandem mass spectra. Mol. Cell. Proteomics 2007, 6 (9), 1638-55.

(34) Tang, W. H.; Shilov, I. V.; Seymour, S. L. Nonlinear fitting method for determining local false discovery rates from decoy database searches. J. Proteome Res. 2008, 7 (9), 3661-7.

(35) Gillet, L. C.; Navarro, P.; Tate, S.; Rost, H.; Selevsek, N.; Reiter, L.; Bonner, R.; Aebersold, R. Targeted data extraction of the MS/MS spectra generated by data-independent acquisition: a new concept for consistent and accurate proteome analysis. Mol. Cell. Proteomics 2012, 11 (6), O111.016717.

(36) Tyanova, S.; Temu, T.; Sinitcyn, P.; Carlson, A.; Hein, M. Y.; Geiger, T.; Mann, M.; Cox, J. The Perseus computational platform for comprehensive analysis of (prote)omics data. Nat. Methods 2016, 13 (9), 731-40.

(37) Huntley, R. P.; Sawford, T.; Mutowo-Meullenet, P.; Shypitsyna, A.; Bonilla, C.; Martin, M. J.; O’Donovan, C. The GOA database: gene Ontology annotation updates for 2015. Nucleic Acids Res. 2015, 43, D1057-D1063.

(38) Hornbeck, P. V.; Zhang, B.; Murray, B.; Kornhauser, J. M.; Latham, V.; Skrzypek, E. Phospho Site Plus, 2014: mutations, PTMs and recalibrations. Nucleic Acids Res. 2015, 43, D512-D520.

(39) Oughtred, R.; Stark, C.; Breitkreutz, B. J.; Rust, J.; Boucher, L.; Chang, C.; Kolas, N.; O’Donnell, L.; Leung, G.; McAdam, R.; Zhang, F.; Dolma, S.; Willems, A.; Coulombe-Huntington, J.; ChatrAryamontri, A.; Dolinski, K.; Tyers, M. The BioGRID interaction database: 2019 update. Nucleic Acids Res. 2019, 47 (D1), D529-D541.

(40) Keerthikumar, S.; Chisanga, D.; Ariyaratne, D.; Al Saffar, H.; Anand, S.; Zhao, K.; Samuel, M.; Pathan, M.; Jois, M.; Chilamkurti, N.; Gangoda, L.; Mathivanan, S. ExoCarta: A Web-Based Compendium of Exosomal Cargo. J. Mol. Biol. 2016, 428 (4), 688-692.

(41) Pathan, M.; Fonseka, P.; Chitti, S. V.; Kang, T.; Sanwlani, R.; Van Deun, J.; Hendrix, A.; Mathivanan, S. Vesiclepedia 2019: a compendium of RNA, proteins, lipids and metabolites in extracellular vesicles. Nucleic Acids Res. 2019, 47 (D1), D516-D519.

(42) Samaras, P.; Schmidt, T.; Frejno, M.; Gessulat, S.; Reinecke, M.; Jarzab, A.; Zecha, J.; Mergner, J.; Giansanti, P.; Ehrlich, H. C.; Aiche, S.; Rank, J.; Kienegger, H.; Krcmar, H.; Kuster, B.; Wilhelm, M. ProteomicsDB: a multi-omics and multi-organism resource for life science research. Nucleic Acids Res. 2019, 48 (D1), D1153-D1163.

(43) Schwenk, J. M.; Omenn, G. S.; Sun, Z.; Campbell, D. S.; Baker, M. S.; Overall, C. M.; Aebersold, R.; Moritz, R. L.; Deutsch, E. W. The Human Plasma Proteome Draft of 2017: Building on the Human Plasma Peptide Atlas from Mass Spectrometry and Complementary Assays. J. Proteome Res. 2017, 16 (12), 4299-4310.

(44) Uhlen, M.; Fagerberg, L.; Hallstrom, B. M.; Lindskog, C.; Oksvold, P.; Mardinoglu, A.; Sivertsson, A.; Kampf, C.; Sjostedt, E.; Asplund, A.; Olsson, I.; Edlund, K.; Lundberg, E.; Navani, S.; Szigyarto, C. A.; Odeberg, J.; Djureinovic, D.; Takanen, J. O.; Hober, S.; Alm, T.; Edqvist, P. H.; Berling, H.; Tegel, H.; Mulder, J.; Rockberg, J.; Nilsson, P.; Schwenk, J. M.; Hamsten, M.; von Feilitzen, K.; Forsberg, M.; Persson, L.; Johansson, F.; Zwahlen, M.; von Heijne, G.; Nielsen, J.; Ponten, F. Proteomics. Tissue-based map of the human proteome. Science 2015, 347 (6220), 1260419.
(45) Kustatscher, G.; Grabowski, P.; Schrader, T. A.; Passmore, J. B.; Schrader, M.; Rappsilber, J. Co-regulation map of the human proteome enables identification of protein functions. Nat. Biotechnol. 2019, 37 (11), 1361-1371.

(46) Zhou, Y.; Zhou, B.; Pache, L.; Chang, M.; Khodabakhshi, A. H.; Tanaseichuk, O.; Benner, C.; Chanda, S. K. Metascape provides a biologist-oriented resource for the analysis of systems-level datasets. Nat. Commun. 2019, 10 (1), 1523.

(47) Szklarczyk, D.; Gable, A. L.; Lyon, D.; Junge, A.; Wyder, S.; Huerta-Cepas, J.; Simonovic, M.; Doncheva, N. T.; Morris, J. H.; Bork, P.; Jensen, L. J.; Mering, C. V. STRING v11: protein-protein association networks with increased coverage, supporting functional discovery in genome-wide experimental datasets. Nucleic Acids Res. 2019, 47 (D1), D607-D613.

(48) Dammalli, M.; Dey, G.; Madugundu, A. K.; Kumar, M.; Rodrigues, B.; Gowda, H.; Siddaiah, B. G.; Mahadevan, A.; Shankar, S. K.; Prasad, T. S. K. Proteomic Analysis of the Human Olfactory Bulb. OMICS 2017, 21 (8), 440-453.

(49) Yoshikawa, K.; Wang, H.; Jaen, C.; Haneoka, M.; Saito, N.; Nakamura, J.; Adappa, N. D.; Cohen, N. A.; Dalton, P. The human olfactory cleft mucus proteome and its age-related changes. Sci. Rep. 2018, 8 (1), 17170.

(50) Sharma, K.; Schmitt, S.; Bergner, C. G.; Tyanova, S.; Kannaiyan, N.; Manrique-Hoyos, N.; Kongi, K.; Cantuti, L.; Hanisch, U. K.; Philips, M. A.; Rossner, M. J.; Mann, M.; Simons, M. Cell type- and brain region-resolved mouse brain proteome. Nat. Neurosci. 2015, 18 (12), 1819-31.

(51) Tepe, B.; Hill, M. C.; Pekarek, B. T.; Hunt, P. J.; Martin, T. J.; Martin, J. F.; Arenkiel, B. R. Single-Cell RNA-Seq of Mouse Olfactory Bulb Reveals Cellular Heterogeneity and Activity-Dependent Molecular Census of Adult-Born Neurons. Cell Rep. 2018, 25 (10), 26892703.

(52) von Eichborn, J.; Dunkel, M.; Gohlke, B. O.; Preissner, S. C.; Hoffmann, M. F.; Bauer, J. M.; Armstrong, J. D.; Schaefer, M. H.; Andrade-Navarro, M. A.; Le Novere, N.; Croning, M. D.; Grant, S. G.; van Nierop, P.; Smit, A. B.; Preissner, R. SynSysNet: integration of experimental data on synaptic protein-protein interactions with drugtarget relations. Nucleic Acids Res. 2012, 41, D834-D840.

(53) Croning, M. D.; Marshall, M. C.; McLaren, P.; Armstrong, J. D.; Grant, S. G. G2Cdb: the Genes to Cognition database. Nucleic Acids Res. 2009, 37, D846-D851.

(54) Pirooznia, M.; Wang, T.; Avramopoulos, D.; Valle, D.; Thomas, G.; Huganir, R. L.; Goes, F. S.; Potash, J. B.; Zandi, P. P. SynaptomeDB: an ontology-based knowledgebase for synaptic genes. Bioinformatics 2012, 28 (6), 897-9.

(55) Drummond, E.; Nayak, S.; Faustin, A.; Pires, G.; Hickman, R. A.; Askenazi, M.; Cohen, M.; Haldiman, T.; Kim, C.; Han, X.; Shao, Y.; Safar, J. G.; Ueberheide, B.; Wisniewski, T. Proteomic differences in amyloid plaques in rapidly progressive and sporadic Alzheimer's disease. Acta Neuropathol. 2017, 133 (6), 933-954.

(56) Lachen-Montes, M.; Fernandez-Irigoyen, J.; Santamaria, E. Deconstructing the molecular architecture of olfactory areas using proteomics. Proteomics: Clin. Appl. 2016, 10, 1178.

(57) Lachen-Montes, M.; Gonzalez-Morales, A.; de Morentin, X. M.; Perez-Valderrama, E.; Ausin, K.; Zelaya, M. V.; Serna, A.; Aso, E.; Ferrer, I.; Fernandez-Irigoyen, J.; Santamaria, E. An early dysregulation of FAK and MEK/ERK signaling pathways precedes the beta-amyloid deposition in the olfactory bulb of APP/PS1 mouse model of Alzheimer's disease. J. Proteomics 2016, 148, 149-58.

(58) Lachen-Montes, M.; Gonzalez-Morales, A.; Fernandez-Irigoyen, J.; Santamaria, E. Deployment of Label-Free Quantitative Olfactory Proteomics to Detect Cerebrospinal Fluid Biomarker Candidates in Synucleinopathies. Methods Mol. Biol. 2019, 2044, 273-289.

(59) Lachen-Montes, M.; Gonzalez-Morales, A.; Schvartz, D.; Zelaya, M. V.; Ausin, K.; Fernandez-Irigoyen, J.; Sanchez, J. C.; Santamaria, E. The olfactory bulb proteotype differs across frontotemporal dementia spectrum. J. Proteomics 2019, 201, 37-47.

(60) Lachen-Montes, M.; Zelaya, M. V.; Segura, V.; FernandezIrigoyen, J.; Santamaria, E. Progressive modulation of the human 
olfactory bulb transcriptome during Alzheimer s disease evolution: novel insights into the olfactory signaling across proteinopathies. Oncotarget 2017, 8 (41), 69663-69679.

(61) Zelaya, M. V.; Perez-Valderrama, E.; de Morentin, X. M.; Tunon, T.; Ferrer, I.; Luquin, M. R.; Fernandez-Irigoyen, J.; Santamaria, E. Olfactory bulb proteome dynamics during the progression of sporadic Alzheimer's disease: identification of common and distinct olfactory targets across Alzheimer-related co-pathologies. Oncotarget 2015, 6 (37), 39437-56.

(62) Palomino-Alonso, M.; Lachen-Montes, M.; Gonzalez-Morales, A.; Ausin, K.; Perez-Mediavilla, A.; Fernandez-Irigoyen, J.; Santamaria, E. Network-Driven Proteogenomics Unveils an Aging-Related Imbalance in the Olfactory IkappaBalpha-NFkappaB p65 Complex Functionality in Tg2576 Alzheimer's Disease Mouse Model. Int. J. Mol. Sci. 2017, 18 (11), 2260.

(63) Fernandez-Irigoyen, J.; Santamaria, E. Olfactory proteotyping: towards the enlightenment of the neurodegeneration. Neural Regener. Res. 2019, 14 (6), 979-981.

(64) Fraisier, C.; Koraka, P.; Belghazi, M.; Bakli, M.; Granjeaud, S.; Pophillat, M.; Lim, S. M.; Osterhaus, A.; Martina, B.; Camoin, L.; Almeras, L. Kinetic analysis of mouse brain proteome alterations following Chikungunya virus infection before and after appearance of clinical symptoms. PLoS One 2014, 9 (3), No. e91397.

(65) Zhao, Y.; Jamaluddin, M.; Zhang, Y.; Sun, H.; Ivanciuc, T.; Garofalo, R. P.; Brasier, A. R. Systematic Analysis of Cell-Type Differences in the Epithelial Secretome Reveals Insights into the Pathogenesis of Respiratory Syncytial Virus-Induced Lower Respiratory Tract Infections. J. Immunol. 2017, 198 (8), 3345-3364.

(66) Yi, G. Z.; Xiang, W.; Feng, W. Y.; Chen, Z. Y.; Li, Y. M.; Deng, S. Z.; Guo, M. L.; Zhao, L.; Sun, X. G.; He, M. Y.; Qi, S. T.; Liu, Y. W. Identification of Key Candidate Proteins and Pathways Associated with Temozolomide Resistance in Glioblastoma Based on Subcellular Proteomics and Bioinformatical Analysis. Biomed Res. Int. 2018, 2018, 5238760 .

(67) Sabe, A. A.; Dalal, R. S.; Chu, L. M.; Elmadhun, N. Y.; Ramlawi, B.; Bianchi, C.; Sellke, F. W. Preoperative gene expression may be associated with neurocognitive decline after cardiopulmonary bypass. $J$. Thorac. Cardiovasc. Surg. 2015, 149 (2), 613-622 discussion 622-623. (68) Kazuno, A. A.; Ohtawa, K.; Otsuki, K.; Usui, M.; Sugawara, H.; Okazaki, Y.; Kato, T. Proteomic analysis of lymphoblastoid cells derived from monozygotic twins discordant for bipolar disorder: a preliminary study. PLoS One 2013, 8 (2), No. e53855.

(69) Berge, T.; Eriksson, A.; Brorson, I. S.; Hogestol, E. A.; BergHansen, P.; Doskeland, A.; Mjaavatten, O.; Bos, S. D.; Harbo, H. F.; Berven, F. Quantitative proteomic analyses of CD4(+) and CD8(+) T cells reveal differentially expressed proteins in multiple sclerosis patients and healthy controls. Clin. Proteomics 2019, 16, 19.

(70) Wang, J.; Ma, Z.; Carr, S. A.; Mertins, P.; Zhang, H.; Zhang, Z.; Chan, D. W.; Ellis, M. J.; Townsend, R. R.; Smith, R. D.; McDermott, J. E.; Chen, X.; Paulovich, A. G.; Boja, E. S.; Mesri, M.; Kinsinger, C. R.; Rodriguez, H.; Rodland, K. D.; Liebler, D. C.; Zhang, B. Proteome Profiling Outperforms Transcriptome Profiling for Coexpression Based Gene Function Prediction. Mol. Cell. Proteomics 2017, 16 (1), 121134.

(71) Lapek, J. D., Jr.; Greninger, P.; Morris, R.; Amzallag, A.; Pruteanu-Malinici, I.; Benes, C. H.; Haas, W. Detection of dysregulated protein-association networks by high-throughput proteomics predicts cancer vulnerabilities. Nat. Biotechnol. 2017, 35 (10), 983-989.

(72) Goedert, M. Neurodegeneration. Alzheimer's and Parkinson's diseases: The prion concept in relation to assembled Abeta, tau, and alpha-synuclein. Science 2015, 349 (6248), 1255555.

(73) Mayer, U.; Ungerer, N.; Klimmeck, D.; Warnken, U.; Schnolzer, M.; Frings, S.; Mohrlen, F. Proteomic analysis of a membrane preparation from rat olfactory sensory cilia. Chem. Senses 2007, 33 (2), 145-62.

(74) Mortstedt, H.; Karedal, M. H.; Jonsson, B. A.; Lindh, C. H. Screening method using selected reaction monitoring for targeted proteomics studies of nasal lavage fluid. J. Proteome Res. 2013, 12 (1), 234-47.
(75) Simoes, T.; Charro, N.; Blonder, J.; Faria, D.; Couto, F. M.; Chan, K. C.; Waybright, T.; Isaaq, H. J.; Veenstra, T. D.; Penque, D. Molecular profiling of the human nasal epithelium: A proteomics approach. J. Proteomics 2011, 75 (1), 56-69.

(76) Leung, C. T.; Coulombe, P. A.; Reed, R. R. Contribution of olfactory neural stem cells to tissue maintenance and regeneration. Nat. Neurosci. 2007, 10 (6), 720-6.

(77) Borgmann-Winter, K.; Willard, S. L.; Sinclair, D.; Mirza, N.; Turetsky, B.; Berretta, S.; Hahn, C. G. Translational potential of olfactory mucosa for the study of neuropsychiatric illness. Transl. Psychiatry 2015, 5, No. e527.

(78) Murtaza, M.; Shan, J.; Matigian, N.; Todorovic, M.; Cook, A. L.; Ravishankar, S.; Dong, L. F.; Neuzil, J.; Silburn, P.; Mackay-Sim, A.; Mellick, G. D.; Wood, S. A. Rotenone Susceptibility Phenotype in Olfactory Derived Patient Cells as a Model of Idiopathic Parkinson's Disease. PLoS One 2016, 11 (4), No. e0154544.

(79) Matigian, N.; Abrahamsen, G.; Sutharsan, R.; Cook, A. L.; Vitale, A. M.; Nouwens, A.; Bellette, B.; An, J.; Anderson, M.; Beckhouse, A. G.; Bennebroek, M.; Cecil, R.; Chalk, A. M.; Cochrane, J.; Fan, Y.; Feron, F.; McCurdy, R.; McGrath, J. J.; Murrell, W.; Perry, C.; Raju, J.; Ravishankar, S.; Silburn, P. A.; Sutherland, G. T.; Mahler, S.; Mellick, G. D.; Wood, S. A.; Sue, C. M.; Wells, C. A.; Mackay-Sim, A. Diseasespecific, neurosphere-derived cells as models for brain disorders. Dis. Models \&amp; Mech. 2010, 3 (11-12), 785-98.

(80) Macron, C.; Lane, L.; Nunez Galindo, A.; Dayon, L. Deep Dive on the Proteome of Human Cerebrospinal Fluid: A Valuable Data Resource for Biomarker Discovery and Missing Protein Identification. J. Proteome Res. 2018, 17 (12), 4113-4126.

(81) Guldbrandsen, A.; Vethe, H.; Farag, Y.; Oveland, E.; Garberg, H.; Berle, M.; Myhr, K. M.; Opsahl, J. A.; Barsnes, H.; Berven, F. S. In-depth characterization of the cerebrospinal fluid (CSF) proteome displayed through the CSF proteome resource (CSF-PR). Mol. Cell. Proteomics 2014, 13 (11), 3152-63.

(82) Ethell, D. W. Disruption of cerebrospinal fluid flow through the olfactory system may contribute to Alzheimer's disease pathogenesis. J. Alzheimer's Dis. 2014, 41 (4), 1021-30.

(83) Brunert, D.; Kurtenbach, S.; Isik, S.; Benecke, H.; Gisselmann, G.; Schuhmann, W.; Hatt, H.; Wetzel, C. H. Odorant-dependent generation of nitric oxide in Mammalian olfactory sensory neurons. PLoS One 2009, 4 (5), No. e5499.

(84) Moon, C.; Yoo, J. Y.; Matarazzo, V.; Sung, Y. K.; Kim, E. J.; Ronnett, G. V. Leukemia inhibitory factor inhibits neuronal terminal differentiation through STAT3 activation. Proc. Natl. Acad. Sci. U. S. A. 2002, 99 (13), 9015-20.

(85) Victores, A. J.; Chen, M.; Smith, A.; Lane, A. P. Olfactory loss in chronic rhinosinusitis is associated with neuronal activation of c-Jun $\mathrm{N}$ terminal kinase. Int. Forum Allergy Rhinol 2018, 8 (3), 415-420.

(86) Islam, Z.; Amuzie, C. J.; Harkema, J. R.; Pestka, J. J. Neurotoxicity and inflammation in the nasal airways of mice exposed to the macrocyclic trichothecene mycotoxin roridin a: kinetics and potentiation by bacterial lipopolysaccharide coexposure. Toxicol. Sci. 2007, 98 (2), 526-41.

(87) Nan, B.; Getchell, M. L.; Partin, J. V.; Getchell, T. V. Leukemia inhibitory factor, interleukin-6, and their receptors are expressed transiently in the olfactory mucosa after target ablation. J. Comp. Neurol. 2001, 435 (1), 60-77.

(88) Taga, T.; Fukuda, S. Role of IL-6 in the neural stem cell differentiation. Clin. Rev. Allergy Immunol. 2005, 28 (3), 249-56.

(89) Corps, K. N.; Islam, Z.; Pestka, J. J.; Harkema, J. R. Neurotoxic, inflammatory, and mucosecretory responses in the nasal airways of mice repeatedly exposed to the macrocyclic trichothecene mycotoxin roridin A: dose-response and persistence of injury. Toxicol. Pathol. 2010, 38 (3), 429-51.

(90) Ueha, R.; Shichino, S.; Ueha, S.; Kondo, K.; Kikuta, S.; Nishijima, H.; Matsushima, K.; Yamasoba, T. Reduction of Proliferating Olfactory Cells and Low Expression of Extracellular Matrix Genes Are Hallmarks of the Aged Olfactory Mucosa. Front. Aging Neurosci. 2018, 10, 86. 
(91) Murphy, C.; Schubert, C. R.; Cruickshanks, K. J.; Klein, B. E.; Klein, R.; Nondahl, D. M. Prevalence of olfactory impairment in older adults. JAMA 2002, 288 (18), 2307-12.

(92) Lopez-Gonzalez, I.; Schluter, A.; Aso, E.; Garcia-Esparcia, P.; Ansoleaga, B.; LLorens, F.; Carmona, M.; Moreno, J.; Fuso, A.; PorteroOtin, M.; Pamplona, R.; Pujol, A.; Ferrer, I. Neuroinflammatory signals in Alzheimer disease and APP/PS1 transgenic mice: correlations with plaques, tangles, and oligomeric species. J. Neuropathol. Exp. Neurol. 2015, 74 (4), 319-44.

(93) Meadowcroft, M. D.; Connor, J. R.; Yang, Q. X. Cortical iron regulation and inflammatory response in Alzheimer's disease and APPSWE/PS1DeltaE9 mice: a histological perspective. Front. Neurosci. 2015, 9, 255.

(94) Davies, D. C.; Brooks, J. W.; Lewis, D. A. Axonal loss from the olfactory tracts in Alzheimer's disease. Neurobiol. Aging 1993, 14 (4), 353-7.

(95) Bathini, P.; Mottas, A.; Jaquet, M.; Brai, E.; Alberi, L. Progressive signaling changes in the olfactory nerve of patients with Alzheimer's disease. Neurobiol. Aging 2019, 76, 80-95.

(96) Scherfler, C.; Schocke, M. F.; Seppi, K.; Esterhammer, R.; Brenneis, C.; Jaschke, W.; Wenning, G. K.; Poewe, W. Voxel-wise analysis of diffusion weighted imaging reveals disruption of the olfactory tract in Parkinson's disease. Brain 2006, 129 (2), 538-542.

(97) Doty, R. L. Olfactory dysfunction in neurodegenerative diseases: is there a common pathological substrate? Lancet Neurol. 2017, 16 (6), $478-488$.

(98) Adhikari, S.; Sharma, S.; Ahn, S. B.; Baker, M. S. In Silico Peptide Repertoire of Human Olfactory Receptor Proteomes on HighStringency Mass Spectrometry. J. Proteome Res. 2019, 18 (12), 4117-4123.

(99) Mainland, J. D.; Keller, A.; Li, Y. R.; Zhou, T.; Trimmer, C.; Snyder, L. L.; Moberly, A. H.; Adipietro, K. A.; Liu, W. L.; Zhuang, H.; Zhan, S.; Lee, S. S.; Lin, A.; Matsunami, H. The missense of smell: functional variability in the human odorant receptor repertoire. Nat. Neurosci. 2014, 17 (1), 114-20.

(100) Feldmesser, E.; Olender, T.; Khen, M.; Yanai, I.; Ophir, R.; Lancet, D. Widespread ectopic expression of olfactory receptor genes. BMC Genomics 2006, 7, 121.

(101) Zhang, C.; Wei, X.; Omenn, G. S.; Zhang, Y. Structure and Protein Interaction-Based Gene Ontology Annotations Reveal Likely Functions of Uncharacterized Proteins on Human Chromosome 17. J. Proteome Res. 2018, 17 (12), 4186-4196.

(102) Melaine, N.; Com, E.; Bellaud, P.; Guillot, L.; Lagarrigue, M.; Morrice, N. A.; Guevel, B.; Lavigne, R.; Velez de la Calle, J. F.; Dojahn, J.; Pineau, C. Deciphering the Dark Proteome: Use of the Testis and Characterization of Two Dark Proteins. J. Proteome Res. 2018, 17 (12), 4197-4210.

(103) Duek, P.; Gateau, A.; Bairoch, A.; Lane, L. Exploring the Uncharacterized Human Proteome Using neXtProt. J. Proteome Res. 2018, 17 (12), 4211-4226.

(104) Duek, P.; Lane, L. Worming into the Uncharacterized Human Proteome. J. Proteome Res. 2019, 18 (12), 4143-4153. 